Rita de Cássia do Amaral

\title{
Qualidade de vida do paciente transplantado renal submetido à ampliação vesical
}

Dissertação apresentada à Faculdade de Medicina da Universidade de São Paulo para obtenção do título de Mestre em Ciências

Área de concentração: Nefrologia Orientador: Prof. Dr. Elias David Neto 


\section{DEDICATÓRIA}

Aos meus pais José e Zelinda, de quem a possibilidade de estudo lhes fora tirada, devido às circunstâncias da vida, mas que em nenhum momento deixaram que isso acontecesse comigo.

Aos meus irmãos Rosana e Ronaldo, eternos cúmplices na vida cujos laços jamais se desfarão.

A todos os pacientes da UTR que gentil e bravamente compartilharam seus temores, expectativas e esperanças de uma vida melhor. 


\section{AGRADECIMENTOS}

Ao Prof. Dr. Elias David Neto que possibilitou essa trajetória em minha vida. A ele, minha gratidão e admiração!

À Maria de Fátima Alves, secretária do Transplante Renal, pela amizade, pelo colo nos momentos difíceis e por me fazer rir em qualquer momento, minha gratidão e amor.

A toda equipe de pós-graduação da Nefrologia e em especial ao Prof. Dr. Rui Toledo de Barros e a secretária Eliana, que pacientemente me conduziram nesse percurso.

Á Adriana, estatística que pacientemente me ajudou com tantos cálculos e entendeu minhas limitações nessa área, muito obrigada!

A todos os funcionários da Urologia e Transplante Renal, muito obrigada por todo o suporte durante essa caminhada. 


\begin{abstract}
À bibliotecária da Clínica Urológica, Marta Maria da Silva, por seu auxílio no levantamento bibliográfico, meu muito obrigada!
\end{abstract}

À Valéria de Vilhena Lombardi, bibliotecária da Faculdade de Medicina, muito obrigada por sua ajuda em momentos tão críticos. 


\section{SUMÁRIO}

Lista de Abreviaturas

Lista de Tabelas

Resumo

Summary

1- INTRODUÇÃO

1.1 - The World Health Organization Quality of Life Instrument

(WHOQOL)

1.2 - Pesquisas Desenvolvidas com WHOQOL........................................ 9

1.3 - Ampliação Vesical ........................................................................ 12

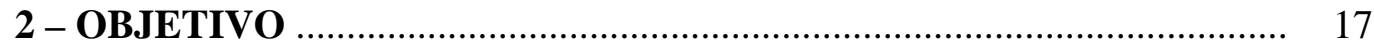

2.1 - Primário................................................................................................ 17

2.2 - Secundário ................................................................................. 17

3 - CASUÍSTICA E MÉTODO................................................................ 18

3.1 - Sujeitos ................................................................................ 18

3.1.1 - Grupo Caso ................................................................... 18

3.1.1.1 - Critérios de Inclusão .............................................. 18

3.1.1.2 - Critérios de Exclusão ................................................ 19

3.1.2 - Grupo Controle ................................................................. 19

3.1.3 - Outras Definições ................................................................ $\quad 20$

3.2 - Instrumento............................................................................. 21

3.2.1 - WHOQOL-Abreviado .................................... 21

3.2.2 - Cálculo do WHOQOL-Abreviado ....................................... 24

3.3 - Análise Estatística ......................................................................... 25

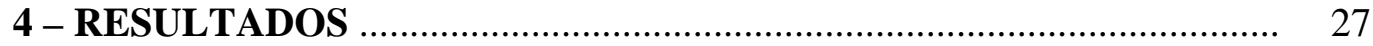

4.1 - População .................................................................................... 27

4.2 - Caracterização da População ........................................................... 28

4.3 - Qualidade de Vida ..................................................................... 32

4.3.1 - Questões Gerais ................................................................. 33 
4.3.2 - Correlação entre os Domínios do WHOQOL-Abreviado e

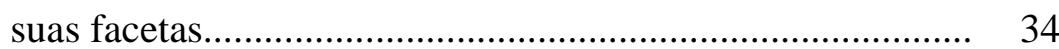

4.3.2.1 - Correlação com Domínio Físico............................. 35

4.3.2.2 - Correlação com Domínio Psicológico ................... 38

4.3.2.3 - Correlação com Domínio Relações Sociais .......... 40

4.3.2.4 - Correlação com Domínio Meio Ambiente ............ 42

4.3 .3 - Outras Correlações ............................................................... 44

4.3.4 - Outros Resultados ............................................................ 45

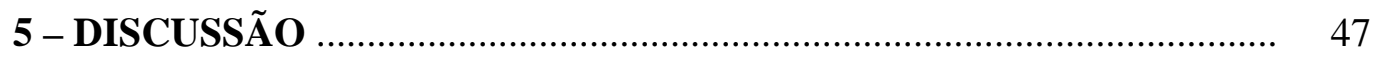

5.1 - Aspectos Gerais ...................................................................... 47

5.2 - Qualidade de Vida .................................................................... 50

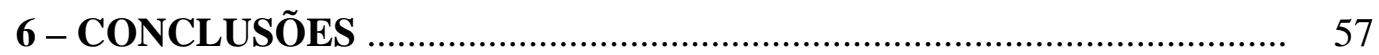

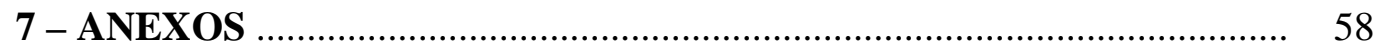

Anexo A - Termo de Consentimento Livre e Esclarecido ........................ 58

Anexo B - WHOQOL- Abreviado.......................................................... 60

Anexo C - Ficha de Caracterização do Sujeito ........................................ 65

Anexo D - Síntese Estatística para Cálculo do WHOQOL-Abreviado .... 68

8 - REFERÊNCIAS BIBLIOGRÁFICAS.................................................... 69

9 - BIBLIOGRAFIAS CONSULTAS ….................................................... 79 


\section{LISTA DE TABELAS}

Tabela 1: Domínios e facetas do WHOQOL-Abreviado ...................................... 8

Tabela 2: População ........................................................................................... 2

Tabela 3: Caracterização demográfica e socioeconômica dos sujeitos ............... 29

Tabela 4: Dados do Transplante .......................................................................... $\quad 30$

Tabela 5: Medicação Imunossupressora ......................................................... 30

Tabela 6: Dados da ampliação vesical.......................................................... 31

Tabela 7: Comparação dos grupos com os domínios do WHOQOL-

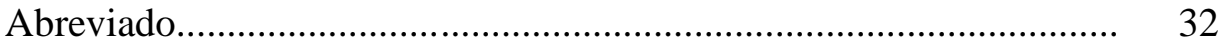

Tabela 8: Comparação dos grupos com as questões gerais ................................ 33

Tabela 9: Respostas categóricas da questão 1.................................................... 34

Tabela 10: Respostas categóricas da questão 2 ................................................ 34

Tabela 11: Correlação entre as facetas e o domínio físico de acordo com o grupo

Tabela 12: Correlação entre as facetas e o domínio psicológico de acordo com o grupo

Tabela 13: Correlação entre as facetas e o domínio relações sociais de acordo com o grupo.

Tabela 14: Correlação entre as facetas e o domínio meio ambiente de acordo com o grupo 


\section{Lista de Abreviaturas}

$\begin{array}{ll}\text { AV } & \text { Ampliação Vesical } \\ \text { BN } & \text { Bexiga Neurogênica } \\ \text { IRCT } & \text { Insuficiência Renal Crônica Terminal } \\ \text { OMS } & \text { Organização Mundial da Saúda } \\ \text { SM } & \text { Salário Mínimo } \\ \text { SPSS } & \text { Statiscal Package for Social Science } \\ \text { TCLE } & \text { Termo de Consentimento Livre e Esclarecido } \\ \text { URT } & \text { Unidade de Transplante Renal }\end{array}$




\section{RESUMO}

Amaral RC. Qualidade de vida do paciente transplantado renal submetido à ampliação vesical [dissertação]. São Paulo: Faculdade de Medicina, Universidade de São Paulo; 2008.

INTRODUÇÃO: A avaliação da Qualidade de Vida tem se destacado de modo crescente em pesquisas clínicas de pacientes com transplante renal. O WHOQOLAbreviado é um dos instrumentos usados para avaliar a Qualidade de Vida em várias populações. O objetivo deste estudo foi avaliar e comparar a Qualidade de Vida nos pacientes transplantados renais submetidos à ampliação vesical e transplantados renais utilizando o WHOQOL-Abreviado e verificar a co-interferência de outros fatores sua Qualidade de Vida desses grupos. MÉTODOS: este é um estudo caso-controle e foi realizado na Unidade de Transplante Renal da Divisão de Clínica Urológica do Instituto Central da Faculdade de Medicina da Universidade de São Paulo, de julho a novembro de 2007. Foram incluídos no estudo todos os pacientes transplantados renais submetidos à Ampliação Vesical entre 1972 e 2004 com enxerto funcionante (Grupo Caso) e seus respectivos pares (Grupo Controle). Participaram 15 pacientes no Grupo Caso e 27 no Grupo Controle. Através do prontuário médico e de uma ficha de caracterização foram coletados os dados demográficos, sociais e econômicos. A Qualidade de Vida foi avaliada apenas uma vez durante a entrevista com a pesquisadora. RESULTADOS: Os 
grupos foram muito semelhantes entre si na maioria das variáveis analisadas. No Grupo Caso observou-se menor renda pessoal $(p=0,013)$ e menor IMC $(p=0,022)$. A avaliação da Qualidade de Vida foi semelhante em quase todos os domínios do WHOQOLAbreviado, a única diferença ocorreu no Domínio Relações Sociais, onde o Grupo Caso teve um escore menor que o Grupo Controle $(p=0,058)$. Houve uma integração significativa entre o Domínio Relações Sociais e a faceta suporte (apoio) social ( $r=0,703 ; p=0,004)$. CONCLUSÃO: A Qualidade de Vida foi muito semelhante entre os dois grupos de transplantados renais. O Grupo Caso apresentou menor resultado no Domínio Relações Sociais, sendo que esse resultado parece estar diretamente ligado à particularidade da patologia urológica do grupo.

Descritores: 1. Qualidade de vida 2. Transplante Renal/Psicologia 3. Bexiga urinária/cirurgia 4. Questionários 


\section{SUMMARY}

Amaral RC. Quality of life of the renal transplant patients with bladder augmentation [dissertation]. Faculty of Medicine, University of São Paulo, SP (Brazil); 2008.

The evaluation of health-related Quality of Life is fundamental when searching for better treatment in renal transplantation. The WHOQOL-Bref is used questionnaire to assessment for many population. The purpose of this study was evaluated and compared the Quality of Life of renal transplant patients with bladder augmentation using WHOQOL-Bref and check the co-interference of other factors their Quality of Life of these groups. METHODS: This is case-control study, performed in a Unit of Renal Transplant of the Division of Urology of the Central Institute of the Hospital of the Clinics of the College of Medicine of the University of São Paulo. Were included in the study all patients of the renal transplant with bladder augmentation between 1972 and 2004 with functioning graft (Case Group) and their peers (Control Group). Fifteen Case Group and 27 Control Group patients were enrolled. Through the medical records and a form of characterization data were collected demographic, social and economic. The Quality of Life was assessed once an interview with one of the authors. RESULTS: Both groups were very similar in most of the analyzed domains. In Case Group if it was observed lower personal income $(\mathrm{p}=0,013)$ and lower BMI $(\mathrm{p}=0,022)$. The assessment 
of Quality of Life was similar in almost all areas of WHOQOL-Bref, the only difference occurred in Social Relations Domains, where the Case Group if had a score lower than the Control Group $(\mathrm{p}=0,058)$. There was a significant integration between the Social Relations Domains facet support social $(r=0,703$ and $p=0,004)$. CONCLUSION: The Quality of Life was very similar between the two groups of renal transplant. The Case Group presented result in lower Social Relations Domains, and that outcome appears to be directly connected to the peculiarity of urological pathology of the group

Descritores: 1. Quality of life 2. Kidney transplant/Psychology 3. Urinary bladder/ surgery 4. Questionnaires 


\section{1 - INTRODUÇÃO}

O interesse em definir e medir Qualidade de Vida é crescente atualmente. As ciências sociais já têm tradição em pesquisa e análise teórica sobre o que seja a Qualidade de Vida. Esta especialidade restringia-se a filósofos, teólogos e cientistas sociais e voltava-se à busca da satisfação com a vida ou à boa vida, além de realizar pesquisas de indicadores sociais (1). A pesquisa sobre Qualidade de Vida está mais ampla atualmente. Ela inclui muitas áreas, como a Sociologia (2), Psicologia (3), Geografia (4), Economia (5), Medicina (6), Farmácia (7), temas ambientais (8) e comunitários (9). Contudo, ainda não há consenso sobre o que é Qualidade de Vida.

O termo Qualidade de Vida é relativamente novo no campo da saúde, somente nos anos 70 é que surgiu na literatura (10). No entanto, a necessidade crescente de avaliar procedimentos médicos fez com que esse termo fosse também cada vez mais utilizado, sendo que o uso freqüente da expressão "Qualidade de Vida" levou a uma dificuldade de encontrar-se uma definição consensual.

As questões relacionadas ao bem-estar subjetivo começaram a ganhar importância na área da saúde, à medida que a expectativa de vida aumentou e, com ela, a incidência de doenças crônicas (11).

Estudos foram feitos para avaliar o desempenho de muitos tipos de medicamentos e terapias usando-se referências biológicas, como por exemplo, a redução da pressão sanguínea. Entretanto, vem crescendo a tendência de considerar que tais avaliações de desempenho não refletem a realidade das experiências dos 
pacientes, já que a perspectiva médica tende a focalizar intensamente os resultados clínicos da avaliação de sinais e sintomas das doenças (12).

Qualidade de vida relacionada à saúde ("Health-related quality of life”) estado subjetivo de saúde ("Subjetive health status"), para Fleck, são conceitos afins, centrados na avaliação subjetiva do paciente. Entretanto, eles estão necessariamente ligados ao impacto do estado de saúde sobre o viver pleno do indivíduo (13). Autores defendem que o termo Qualidade de Vida é mais amplo e inclui uma variedade maior de condições que podem afetar a percepção do indivíduo, os seus sentimentos e os comportamentos relacionados com o seu dia-a-dia, abrangendo a sua condição de saúde e intervenções médicas, mas não se restringindo a elas (14).

Conceituar Qualidade de Vida é uma tarefa complexa, pois envolve a questão da subjetividade. Em geral, os autores referem-se à necessidade de considerar várias dimensões da Qualidade de Vida, como os aspectos físicos, emocionais e sociais, à semelhança do conceito de saúde elaborado pela Organização Mundial de Saúde, no qual a saúde é considerada como um completo bem-estar físico, mental e social, e não simplesmente a ausência de enfermidade (15).

Uma aproximação conceitual de Qualidade de Vida foi proposta por Marques. Nessa proposta que os objetivos das teorias e práticas psicológicas podem ser traduzidos pela busca de um alto patamar de qualidade vida, pretendendo-se que homens e mulheres tenham bem-estar físico e psicológico, satisfação com suas vidas como um todo, "ainda que não seja possível eliminar o sofrimento totalmente", pois este faz parte do processo vital (16).

Barros propõe que a Qualidade de Vida é a valorização que uma pessoa faz sob vários aspectos que considera importantes em sua vida atual e em termos 
globais. Assim, parte de uma concepção subjetiva, em que a Qualidade de Vida é compreendida como um construto que só pode ser avaliado a partir da ótica e percepção verbalizada pelo indivíduo (17).

Há uma tendência em abordar o tema Qualidade de Vida de forma multidimensional, integrando indicadores objetivos, que relatam a experiência de vida concreta, observável, aos aspectos subjetivos (18). Acrescenta-se a este construto multidimensional, a dimensão espiritual e questiona a possibilidade desta dimensão ser globalizante, estabelecendo a valoração de vários aspectos de vida da pessoa (16).

Qualidade de Vida, segundo grupo de Qualidade de Vida da Organização Mundial da Saúde, é definida como "a percepção do indivíduo de sua posição na vida no contexto da cultura e do sistema de valores nos quais ele vive e em relação aos seus objetivos, expectativas, padrões e preocupações" (p. 1405). Este conceito enfatiza a avaliação subjetiva da Qualidade de Vida e a percepção que o paciente tem do seu estado físico, emocional e social (19).

Esta definição da Organização Mundial da Saúde (OMS) foi eleita como norteadora para a presente pesquisa sobre Qualidade de Vida em paciente transplantado renal submetido à ampliação vesical.

Segundo Fleck, a avaliação de Qualidade de Vida tem recebido uma crescente importância na literatura médica, sendo valorizados não só os aspectos relativos à doença, mas a perspectiva do paciente em relação à sua vida. $\mathrm{O}$ autor classifica os instrumentos para avaliar a Qualidade de Vida em três categorias, conforme a perspectiva que eles se propõem a analisar: instrumentos que avaliam a 
Qualidade de Vida geral; que avaliam a Qualidade de Vida ligada à saúde e que avaliam a Qualidade de Vida ligada a uma doença específica (20).

Qualidade de vida geral - surgiu a partir do referencial social e aponta, de igual maneira para diferentes componentes presentes no construto Qualidade de Vida, em diferentes grupos, culturas e sociedades. Essa perspectiva oferece elementos tanto para a compreensão dos desejos, motivações, recursos e oportunidades disponíveis para o bem-estar de uma pessoa e sua satisfação, quanto às suas realizações em diferentes domínios. Neste grupo encontra-se o World Health Organization Quality of Life Instrument (WHOQOL) em sua versão longa, com 100 questões, e sua versão breve, com 26 questões. A versão abreviada será utilizada no presente trabalho. Além destes existem muitos outros, como por exemplo: Satisfaction with Life Domain Scale (SLDS), Quality of Life Checklist (QLC), e Quality of Life Index for Mental Health (QLI-MH).

Qualidade de vida ligada à saúde (“Health related quality of life”) - a ênfase recai no impacto específico que a prevenção e o tratamento têm sobre o bemestar. Focaliza “status” funcional, mas dentro das dimensões ligadas aos aspectos diretamente relacionados com a saúde, por exemplo, limitações decorrentes de doenças emocionais ou físicas, sem considerar as limitações decorrentes da pobreza ou de restrições sociais. Estes instrumentos cobrem os aspectos de vida afetados pelo fato de estar doente. Alguns exemplos: Notingham Health Profile, Medical Outcomes Study-Short Form (MOS SF-36), Sickness Impact Profile e Quality of Well-Being.

Qualidade de vida ligada à doença específica - a ênfase recai sobre aspectos específicos de determinada doença em relação à qualidade de vida. No caso 
de depressão, por exemplo, há Quality of Life Depression Scale (QLDS), cuja versão está sendo validada para o Português e, especificamente para o transplante renal existe o Kidney Transplant Questionnaire (KTQ), ainda não validado para o Português.

Mesmo existindo muitos instrumentos para avaliar a Qualidade de Vida, a natureza subjetiva e dinâmica da mesma acaba criando dificuldades para sua mensuração, de forma que pesquisas nessa área têm produzido resultados aparentemente contraditórios.

Barros considera a monitorização da Qualidade de Vida um recurso científico imprescindível para acompanhamento de estudos clínicos em várias doenças crônicas como a insuficiência renal, reumatológicas, oncológicas, cardiológicas e outras. Assim, a utilização de escalas para avaliar a Qualidade de Vida dos pacientes com doenças crônicas, malignas ou não, pode ser um importante recurso para a qualificação dos serviços de atendimento, com repercussões tanto na otimização de custos com a saúde, como na satisfação dos pacientes (17). 


\section{1 - “The World Health Organization Quality of Life Instrument (WHOQOL)”}

A constatação de que não havia nenhum instrumento que avaliasse Qualidade de Vida dentro de uma perspectiva transcultural e internacional, motivou a Organização Mundial da Saúde (OMS) a desenvolver um instrumento com estas características (19). Na definição de Qualidade de Vida proposta pelo grupo fica implícito que o conceito de Qualidade de Vida é subjetivo, multidimensional e que inclui elementos de avaliação tanto positivos (por ex. mobilidade) como negativos (por ex. dor).

Para a OMS, uma avaliação ideal da saúde deveria incluir, além das avaliações de saúde física, uma avaliação da Qualidade de Vida que abrangesse várias áreas da vida, chamadas domínios, tais como a dimensão física, psicológica, social e espiritual (21). Mais do que a necessidade de implementar um instrumento de medida internacional de Qualidade de Vida, a OMS preocupou-se em introduzir um aspecto humanístico no cuidado com a saúde, promovendo uma abordagem holística. Para autores como Barros, esta preocupação com o estudo, o entendimento e a mensuração da Qualidade de Vida representa uma mudança de paradigma também em termos de avaliação da efetividade dos tratamentos (15).

A partir dessas perspectivas foi desenvolvido o "World Health Organization Quality of Life Instrument" - 100 (WHOQOL-100) e sua versão abreviada WHOQOL-Bref. Esses instrumentos foram desenvolvidos em colaboração com instituições espalhadas pelo mundo e foram amplamente testadas em campo. Eles podem ser empregados em diferentes situações culturais permitindo que os 
resultados possam ser comparados mesmo entre populações e países diferentes. Esse instrumento está atualmente disponível em 20 idiomas diferentes (22).

O WHOQOL-100 foi desenvolvido em quatro etapas:

1. Definição do conceito de Qualidade de Vida, anteriormente apresentado;

2. Escolha de 15 centros de estudos, culturalmente diferentes, ao redor do mundo, para a tarefa de selecionar os aspectos mais relevantes que melhor pudessem medir a Qualidade de Vida;

3. Seleção de 300 questões abrangendo 29 aspectos que formou a base para a realização da medida de Qualidade de Vida e aplicação do estudo piloto com no mínimo 300 participantes;

4. Teste de campo aplicado após a seleção de 100 questões com escala de respostas equivalentes nas diferentes línguas.

O WHOQOL-100 é constituído de 100 questões agrupadas em 24 itens também chamada de facetas, abrangendo 6 domínios (físico, psicológico, nível de independência, relações sociais, ambiente e aspectos religiosos/religiões/crenças pessoais.

O desenvolvimento da versão em Português dos dois instrumentos seguiu a metodologia proposta pela Organização Mundial da Saúde, conforme Fleck e colaboradores $(13,20)$.

A versão brasileira do WHOQOL-100 foi analisada em relação às seguintes características psicométricas: consistência interna; validade; validade de critérios; validade concorrente; confiabilidade do teste-reteste. 
A necessidade de instrumentos curtos que demandem pouco tempo para seu preenchimento, mas com característica psicométricas satisfatórias, fez com que a OMS desenvolvesse uma versão concisa do WHOQOL-100, o WHOQOL-Bref ou abreviado (20).

O WHOQOL-Abreviado foi desenvolvido com o apoio de vinte centros de estudos situados em dezoito países. Ele consta de 26 questões, sendo uma pergunta para avaliar a Qualidade de Vida geral, uma pergunta para avaliar a saúde geral e as demais 24 representam cada uma das facetas que compõe o instrumento original (Tabela 1). O instrumento foi desenvolvido a partir da premissa de que a Qualidade de Vida é um construto multidimensional, havendo, portanto, maior coerência ao considerar cada domínio e respectivo escore individualmente.

Tabela 1 - Domínios e facetas do WHOQOL-Abreviado

\begin{tabular}{ll}
\hline Domínio & 1 - Domínio Físico \\
3. & Dor e desconforto \\
10. & Energia e fadiga \\
16. & Sono e repouso \\
15. & Mobilidade \\
17. & Atividades da vida cotidiana \\
4. & Dependência de medicação ou de tratamentos \\
18. & Capacidade de trabalho \\
\hline Domínio & - Domínio Psicológico \\
5. & Sentimentos positivos \\
7. & Pensar, aprender, memória e concentração \\
19. & Auto-estima \\
11. & Imagem corporal e aparência \\
26. & Sentimentos negativos \\
6. & Espiritualidade/religião/crenças pessoais \\
\hline Domínio 3 - Relações Sociais \\
20. & Relações pessoais \\
22. & Suporte (apoio) social \\
21. & Atividade sexual \\
\hline Domínio 4 - Meio Ambiente \\
8. & Segurança física e proteção \\
22. & Ambiente no lar \\
12. & Recursos financeiros \\
24. & Cuidados de saúde e sociais: disponibilidade e qualidade \\
13. & Oportunidades de adquirir novas informações e habilidades \\
14. & Participação em, e oportunidades de recreação/lazer \\
9. & Ambiente físico: (poluição/ruído/trânsito/clima) \\
25. & Transporte \\
\hline
\end{tabular}

Fonte: The WHOQOL Group (21) 
As características psicométricas do WHOQOL-Abreviado, da mesma forma como as do WHOQOL-100, do qual deriva, preenchem os critérios de consistência interna, validade discriminante, validade concorrente, validade de conteúdo e confiabilidade teste-reteste.

\section{2 - Pesquisas Desenvolvidas com WHOQOL}

Em pesquisa realizada na base de dados Medline (1999-2008), observase a grande utilização deste questionário em diferentes áreas da saúde, como radioterapia (23), psicologia (24-26), psiquiatria (27, 28), ortopedia facial (29), hematologia (30), oncologia $(31,32)$, enfermagem (32), odontologia (33) entre outras.

Na mesma base de dados, se encontra, no mesmo período, trabalhos de pesquisa realizados em diferentes países de diferentes culturas, como Tailândia (34), Singapura (35), Holanda (6), Taiwan (32, 36), Alemanha (37), Áustria (38), Itália (39), Turquia (40), Suécia (41), Canadá (42), China (43, 44), Índia (45), Austrália,(46), Israel (47), Malásia (48), Argentina (27) e Rússia (49), entre outros. Demonstrando a transculturalidade e internacionalidade desse instrumento.

$\mathrm{Na}$ Nefrologia, o WHOQOL tem sido aplicado nas opções de tratamento como transplante renal (50) e hemodiálise (36), como observamos nos estudos a seguir.

O WHOQOL mostrou ser um instrumento útil e seguro para medir a Qualidade de Vida em populações diferentes, podendo compará-las objetivamente.

Wesolowski e Szyber compararam a Qualidade de Vida dos pacientes com doença renal em estágio terminal submetidos a transplante renal bem sucedido, 
com a população saudável da Polônia, empregando o WHOQOL-100 na versão polonesa. Observaram que em alguns aspectos da Qualidade Vida de pacientes de transplantados não diferem dos indivíduos saudáveis nas facetas relações sociais, ambiente e religiosidade. Em outras facetas, como auto-estima, sentimentos negativos, atividade sexual e segurança física, a Qualidade de Vida dos pacientes transplantados foi menor que a dos indivíduos saudáveis (51).

Tomasz e Piotr realizaram estudo comparando a Qualidade de Vida de pacientes com doença renal em estágio terminal que fazem hemodiálise com os que fizeram transplante, utilizando o WHOQOL-100. A Qualidade de Vida de vida dos pacientes de transplante foi melhor que dos pacientes de hemodiálise em domínios: relações globais, físicas, sociais e ambiente e também nas facetas: dor e desconforto, energia e fadiga, sentimentos positivos, mobilidade, atividades cotidianas, capacidade de trabalho, relações pessoais, atividade sexual e transporte. No entanto, os pacientes em hemodiálise obtiveram uma melhor Qualidade de Vida na faceta de imagem corporal e aparência (50).

O WHOQOL foi utlizado para verificar a Qualidade de Vida após um procedimento ou tratamento.

Kong IL e Molassiotis realizaram estudo em Hong Kong, objetivando identificar os métodos usados pelos pacientes lidar com tensão depois de transplante renal e avaliar a Qualidade de Vida percebida em dois intervalos de tempo diferentes depois do transplante. A versão chinesa do WHOQOL-100 foi aplicada em 101 pacientes de um centro de transplante, juntamente com uma questão aberta sobre fatores estressores. Os resultados revelaram que o principal estressor identificado foi o medo da rejeição, complacência com medicamento e efeitos colaterais dos 
mesmos, incerteza sobre o futuro, medo de infecção e o fator de custo do tratamento. Mostraram também que a Qualidade de Vida era moderada nesta amostra. Os resultados poderão permitir que as enfermeiras do centro de transplante planejem intervenções e ajudem os receptores a conviver com as demandas de vida com um enxerto renal (43).

Lazzaretti e colaboradores realizaram estudo para verificar a evolução da Qualidade de Vida após o transplante renal, aplicando o WHOQOL-Abreviado em 100 pacientes. Noventa por cento dos pacientes declaram estar satisfeitos com sua condição geral de saúde e 76\% reportaram um bom desempenho para as atividades diárias. A maioria dos indivíduos foi percebida como uma redução ou desaparecimento de sintomas causado pela doença (52).

Em pesquisa realizada no banco de dados Medline (1999-2007), na área urológica, com os termos Quality of life, bladder, foram encontrados 80 artigos. Esses artigos traziam estudos de Qualidade de Vida em pacientes com substituição de bexiga, prostatectomia, câncer de bexiga, câncer de próstata e outras. Os instrumentos utilizados para avaliar Qualidade de Vida nestes estudos foram os mais variados. Em apenas um artigo foi utilizado o WHOQOL-100. Era um estudo piloto no efeito de relaxamento de músculo progressivo que treina o paciente depois de cirurgia de estoma.

Pesquisando no mesmo banco de dados de 1981-2007 com os termos "bladder augmentation" ou" bladder dysfuntion" e "quality of life", foram encontrados 47 artigos e apenas 1 falava sobre Qualidade de Vida em transplante renal com ampliação vesical, mas nenhum instrumento foi utilizado. 
A falta de artigos publicados na área urológica, com a utilização do WHOQOL, pode evidenciar que em tal área o instrumento não é bem difundido.

\section{3 - Ampliação Vesical}

A ampliação vesical foi descrita pela primeira vez utilizando-se de segmentos intestinais (o íleo) por dois italianos, Tizzoni e Froggi em 1888, para ampliar a bexiga de um cachorro.

Mickulicz foi o primeiro a ampliar uma bexiga com baixa capacidade com segmento intestinal, em 1899.

Todavia, esse procedimento não foi muito usado até os anos 50 , quando Couvelaire popularizou tal tratamento para bexigas contraídas por tuberculose (53).

Para pacientes com bexiga neurogênica (BN), a ampliação vesical passou a ser utilizada com a difusão do cateterismo limpo e intermitente para esvaziamento da bexiga (54) e, o uso do exame urodinâmico, permitindo assim, um melhor conhecimento da fisiologia das alterações do trato urinário inferior (55).

A ampliação vesical é indicada em outros casos como esquistossomose, cistite intersticial, radioterapia e em outras cirurgias da bexiga (53).

Para casos de tuberculose, a ampliação vesical tem melhores resultados do que para as outras causas de lesões como $\mathrm{BN}$, hiperatividade detrusora idiopática e doenças inflamatórias (56).

Com relação à $\mathrm{BN}$, segundo Bruschini (57), "entende-se por bexiga neurogênica toda a alteração do funcionamento vesicoesfincteriano decorrente de problemas neurológicos" (p.193). 
Etiologicamente a BN pode ser classificada em congênita ou adquirida. As causas congênitas são encontradas com maior freqüência em criança, principalmente com diagnóstico de mielomeningoceles (58). Entre adultos as causas mais freqüentes são as adquiridas, entre elas: os traumatismos raquimedulares (acidentes automobilísticos, acidentes de trabalho, ferimentos por arma de fogo, e outros), as doenças degenerativas (Parkinson e Alzheimer), e os acidentes vasculares cerebrais.

Seja qual for o motivo da Ampliação Vesical, os pacientes podem ter problemas de incontinência urinária, de infecções urinárias, de calculoses, de resíduo urinário, de refluxo vesicoureteral e de insuficiência renal.

Grande parte das ampliações vesicais da Divisão de Clínica Urológica do Hospital das Clínicas é por BN.

O maior risco dessa patologia é a lesão renal progressiva, principalmente devido ao refluxo vesicoureteral, as infecções recorrentes, entre outras disfunções do trato urinário. $\mathrm{O}$ tratamento tem por objetivo principal prevenir que essa lesão ocorra.

A Unidade de Transplante Renal (UTR) tem realizado vários transplantes nesses pacientes chegando a bons resultados com procedimentos cirúrgicos modernos e eficazes.

Esse serviço é considerado um centro de excelência em procedimentos de ampliação, melhora de complacência e refuncionalização de bexiga em pacientes candidatos a transplante renal e transplantados.

Vários estudos sobre estes procedimentos foram desenvolvidos pela equipe da Urologia e UTR. Em um desses estudos Nahas et al. (59), afirmaram que o serviço tem recebido um número significativo de pacientes que apresentam algum 
tipo de derivação urinária supra-vesical na avaliação pré-transplante, o que os levou à uma desfuncionalização da bexiga. Os autores objetivaram no estudo demonstrar que algumas bexigas desfuncionalizadas mesmo que por longos períodos podem, manter a capacidade, serem reabilitadas em sua função e serem aproveitadas no transplante renal. Tudo isso, sem a necessidade de submeter o paciente a procedimentos cirúrgicos visando o aumento da capacidade vesical. A experiência foi realizada em 3 pacientes de transplante renal em bexigas previamente refuncionalizadas. A reabilitação da bexiga foi realizada através de injeção intermitente de soro fisiológico. O resultado obtido foi um aumento da capacidade vesical média de 110 ml para $220 \mathrm{ml}$. A conclusão do estudo foi de que o transplante renal é um procedimento seguro em desfucionalizadas e apresenta boa resposta dos pacientes desse programa.

Em outro estudo com 12 pacientes com capacidade vesical reduzida ou má complacência vesical, submetidos ao Transplante entre 1985 e julho de 1995. A avaliação urodinâmica foi realizada em todos os pacientes. Os resultados apresentados foram: aumento da capacidade vesical e melhora na complacência.

O grupo afirma que pacientes com doença renal em estágio terminal, devido a significantes problemas do trato urinário inferior não corrigidos antes do Transplante podem aumentar sua morbidade, a mortalidade de receptor e perda de enxerto (60).

Nahas e colaboradores, declaram que as propriedades de armazenamento de uma bexiga com baixa pressão e que habitualmente esvazia-se sem manter resíduo é muito importante para a preservação da área urinária superior. No caso da pressão dentro do reservatório ser alta ou o reservatório não poder ser esvaziado 
adequadamente, comprometerá o rim e a função renal. Tais pacientes foram considerados candidatos pobres para o Transplante. Nos últimos 15 anos, com a aceitação do cateterismo intermitente até mesmo para pacientes transplantados, um conhecimento melhor da fisiologia de bexiga e, o uso de segmentos intestinais para reconstrução vesical, este grupo de pacientes tem uma oportunidade melhor para o Transplante (61).

Outro estudo realizado pela mesma equipe foi apresentado no Second Congress of the International Pediatric Transplant Association. Nesse trabalho, Nahas et al. afirmaram que ampliação vesical é procedimento estabelecido para o tratamento de bexiga disfuncionalizada em pacientes de Transplante. Afirmaram ainda, que uretorocistoplatia combina os benefícios comuns a toda enterocistoplastia sem somar quaisquer de suas complicações ou riscos (62).

Pensando que a Qualidade de Vida tornou-se um ponto central onde a cura está impossibilitada e é nesse contexto que o paciente renal crônico e ampliado vesical se encontram, cita-se Lambert (63).

"o paciente crônico necessita lidar com os sintomas que apresenta, adaptar-se a regimes e restrições, ajustar-se a alterações de imagem corporal, lidar com as incertezas do progresso de seu tratamento e revisar metas pessoais, sociais e ocupacionais" (p. 11).

Diante desse quadro o objetivo do tratamento de doenças crônicas passa a focalizar não somente o controle dos sintomas, mas também, a satisfação do paciente frente ao seu tratamento, seu bem-estar físico e mental proporcionado por este. Portanto, (18) 
“os avanços tecnológicos não bastam por si só como estimativa de eficiência e eficácia, mas principalmente a percepção subjetiva, e a capacidade funcional do paciente devem ser consideradas entre os resultados". (p.7)

Tendo em vista o número de pacientes transplantados com Ampliação Vesical, o grande número de pessoas com problemas urológicos que perderam sua função renal em decorrência deste problema e a escassa produção científica direcionada à Qualidade de Vida dos pacientes que passaram por este procedimento cirúrgico. E ainda, tendo em vista que vários fatores podem interferir em um bom pós- operatório e na manutenção dos tratamentos posteriores ao Transplante e a Ampliação Vesical, possibilitando com isso além de um acréscimo de "anos à vida", um acréscimo de "vida aos anos". Entende-se com isso, que há no presente trabalho, pertinência em sua realização, pois, não só acrescentará a equipe de transplante que já detém o "know-how" das técnicas e procedimentos clínicos e cirúrgicos, como também beneficiará os pacientes. 


\section{2 - OBJETIVO}

\section{1 - Primário}

O objetivo deste estudo é avaliar a Qualidade de Vida em pacientes transplantados renais submetidos à ampliação vesical.

\section{2 - Secundário}

Verificar a co-interferência de outros fatores na Qualidade de Vida em pacientes transplantados renais submetidos à ampliação vesical. 


\section{3 - CASUÍSTICA E MÉTODO}

Este é um estudo caso-controle, a partir do instrumento World Health Organization Quality of Life Instrument - WHOQOL-Bref (versão Português).

\section{1 - Sujeitos}

O estudo foi realizado no ambulatório da Unidade de Transplante Renal (UTR) da Divisão de Clínica Urológica do Instituto Central do Hospital das Clínicas da Faculdade de Medicina da Universidade de São Paulo.

Foram sujeitos todos os pacientes transplantados submetidos à Ampliação Vesical entre 1972 e 2004 com enxerto funcionante (Grupo Caso) e seus respectivos pares (Grupo Controle).

O maior tempo de transplante admitido foi de 16 anos e 2 meses e o menor de 1 ano e 9 meses.

\subsection{1 - Grupo Caso}

\subsubsection{1 - Critérios de Inclusão}

1. Estavam em acompanhamento ambulatorial na UTR, com rim transplantado funcionante;

2. Foram submetidos a qualquer tempo à Ampliação Vesical, neste ou em outro serviço;

3. Apresentaram idade igual ou superior a 18 anos no período da coleta de dados, independente do sexo;

4. Concordaram em participar da pesquisa assinando o Termo de Consentimento Livre e Esclarecido - TCLE (Anexo A). 


\subsubsection{2 - Critérios de Exclusão}

1. Psicose ou demência;

2. Déficit cognitivo;

3. Limitações físicas como: afasia e alterações graves de linguagem;

4. Não concordaram em participar da pesquisa.

\subsection{2 - Grupo Controle}

Foi formado a partir do primeiro e do segundo pacientes encontrados para serem os respectivos pares de um sujeito do grupo caso. Os dois pares deste grupo cumpriram os seguintes requisitos, no período da coleta de dados:

1. Tinham o mesmo sexo;

2. Estavam incluídos dentro da mesma faixa etária do indivíduo caso. As faixas etárias foram definidas, levando-se em conta a distribuição da população economicamente ativa do IBGE ${ }^{1}$.

(1) De 18 a 20 anos;

(2) De 21 a 34 anos;

(3) De 35 a 49 anos;

(4) De 50 a 64 anos e

(5) Maior de 65 anos.

3. Tinham doença de base para a IRCT diferente de uma causa urológica;

4. Tinham função renal no mesmo patamar de creatinina sérica estabelecido para seu par caso, ou seja:
a. Menor ou igual a $1,5 \mathrm{mg} / \mathrm{dl}$;
b. De 1,6 a $2,5 \mathrm{mg} / \mathrm{dl}$;

\footnotetext{
${ }^{1}$ www.ibge.gov.br, acessado em 1 dez. 2005
} 
c) Maior ou igual a 2,6 mg/dl.

5. Recebiam o mesmo tipo de regime imunossupressor;

A data de realização do Transplante foi procurada em um período de mais ou menos 365 dias, obedecendo à seguinte ordem:

a) Se Transplante do sujeito do grupo caso ocorreu até o mês de junho, seu par foi procurado entre os Transplantes ocorridos a partir do mês de julho do mesmo ano e estendido até o mês de junho do ano seguinte;

b) Se o Transplante do sujeito do grupo caso ocorreu a partir do mês de julho, seu par foi procurado entre os Transplantes ocorridos de Junho e anteriores, estendido até o mês de julho do ano anterior.

c) Quando o individuo controle não foi encontrado na ordem estabelecida, esta foi invertida.

\subsection{3 - Outras Definições}

Algumas definições se fazem necessárias para o estudo. São elas:

1. Pacientes que se declaram aposentados, mas exerciam alguma atividade remunerada regularmente, foram considerados ativos do ponto de vista produtivo.

2. Para o estudo, considerou-se escape a perda não significativa de urina (incontinência), mas que no dia-a-dia pode trazer algum tipo de desconforto ao indivíduo. Tais escapes se dão, entre outros motivos, quando um esforço maior é feito ou quando o período 
para a sondagem é ultrapassado, deixando que a bexiga ultrapasse o limite de sua capacidade de armazenamento.

\section{2 - Instrumento}

A coleta de dados foi através da utilização do WHOQOL-Abreviado (Anexo B) e ficha de caracterização do sujeito (Anexo C). Foi também utilizado o prontuário médico do paciente para verificar o preenchimento dos critérios de inclusão.

Os pacientes foram procurados pela pesquisadora no dia da sua consulta médica periódica. Nesse dia foram convidados a participarem da pesquisa, mediante apresentação do projeto e explicação de seu objetivo. Após a leitura e assinatura no TCLE, os instrumentos foram aplicados.

Os pacientes que faltaram às consultas ou as tinham marcadas em datas desfavoráveis à coleta de dados, foram contatados via telefone para um agendamento.

Os instrumentos foram aplicados individualmente pela pesquisadora, às portas fechadas, em um consultório do ambulatório da UTR.

\subsection{1 - WHOQOL-Abreviado}

O WHOQOL-Abreviado é um, utilizado para avaliar Qualidade de Vida de populações adultas, contém 26 perguntas ou facetas das quais 24 são distribuídas em quatro domínios:

1. Físico - percepção do indivíduo sobre sua condição física. As atividades da vida geralmente se referem aos cuidados básicos de 
higiene pessoal e tarefas de auto-cuidado (banhar-se, arrumar-se, locomover-se), associado com tarefas mais complexas que são desempenhadas no dia-a-dia (administração das finanças e medicamentos, utilização do telefone, compras necessárias, preparação da refeição, uso de transporte e desempenho básico na arrumação de casa). Este domínio compreende as facetas: dor e desconforto; energia e fadiga; sono e repouso; atividades da vida cotidiana; dependência de medicação ou de tratamentos; capacidade de trabalho (20).

2. Psicológico - percepção do indivíduo sobre sua condição afetiva e congnitiva. Ou seja, representa o grau de sua satisfação com a vida. Engloba a avaliação de aspectos emocionais como humor e sentimentos, envolvidos tanto na situação da doença como na condição da Qualidade de Vida. É composto pelas facetas: sentimentos positivos; pensar, aprender, memória e concentração; auto-estima; imagem corporal e aparência; sentimentos negativos; espiritualidade/religião/crenças pessoais (20);

3. Relações Sociais - percepção do indivíduo sobre os relacionamentos sociais e os papéis sociais adotados na vida. Ou ainda, são dimensões de bem-estar do indivíduo que considera a maneira como ele interage com as pessoas do seu meio social, de como essas pessoas reagem a ele, e ainda, quais os tipos de relação que ele estabeleceu com as instituições sociais. Engloba 
as facetas: relações pessoais; suporte (apoio) social; atividade sexual (20)

4. Meio Ambiente - percepção do indivícuo sobre aspectos diversos relacionados ao ambiente onde vive, levando em conta a infraestrutura desse ambiente. Contém as facetas: segurança física e proteção; ambiente no lar; recursos financeiros; cuidados de saúde e sociais: disponibilidade e qualidade; oprortunidades de adquirir novas informações e habilidades; participação em, e oportunidades de recreação/lazer; ambiente físico: (poluição/ruído/trânsito/clima); transporte (20).

As questões que compõem o intrumento foram formuladas para uma escala de respostas do tipo Likert (64), com pontuação variando de 1 a 5. As escalas de respostas são:

- intensidade (nada - extremamente);

- capacidade (nada - completamente);

- $\quad$ freqüência (nunca - sempre);

- avaliação (muito insatisfeito - muito satisfeito; muito ruim muito bom).

O WHOQOL-Abreviado é instrumento auto-administrável portanto, a maioria dos pacientes não recebe ajuda em seu preenchimento. Em pelo menos duas situações o instrumento pode ser administrado pelo pesquisador, primeiro quando o responte tiver baixa acuidade visual e, em situação de analfabetismo.

Antes da aplicação, foi enfatizado que todo o questionário referia-se às duas últimas semanas (grifo nosso). 
Quando o respondente não entendia o significado de alguma pergunta, a pesquisadora lia a questão pausadamente, sem dar qualquer esclarecimento de ordem interpretativa e em seguida dava a seguinte instrução: "Agora, escolha entre as alternativas a que lhe parece mais apropriada.”

Para o cálculo dos escores dos domínios, os índices das facetas componentes resumem os domínios aos quais pertencem. Tanto domínios como as duas questões de ordem geral foram medidas em direção positivas, ou seja, escores mais altos denotaram melhor Qualidade de Vida. Para esse cálculo, foi utilizada a síntese estatística (Anexo D) fornecida pelo grupo responsável pela padronização do instrumento no Brasil, através do programa SPSS (Statistical Package for Social Science), disponível no endereço eletrônico http://www.ufrgs.br/psiq/whoqol86.

Os dois grupos foram estudados e analisados separadamente nos quatro domínios do instrumento e nas questões gerais e, depois, comparados entre si.

Os domínios do WHOQOL-Abreviado são compostos por facetas e cada faceta corresponde a uma questão do instrumento, com exceção das questões 1 e 2 que foram desenvolvidas para avaliar aspectos gerais

\subsection{2 - Cálculo do WHOQOL-Abreviado}

O WHOQOL-Abreviado deriva do WHOQOL-100, que apresenta quatro questões para avaliar cada faceta. Na versão abreviada, cada faceta é avaliado a partir de uma única questão. O WHOQOL-Abreviado não permite estabelecer um escore total e sim um resultado por domínios. Por derivar do WHOQOL-100, a base de avaliação é o instrumento completo. A idéia é transformar os resultados equivalentes aos resultados do WHOQOL-100. 
O primeiro passo é estabelecer o valor de cada alternativa escolhida nas questões. Todas as questões, com exceção de três (Q3, Q4 e Q26), são respondidas em direção positiva, ou seja, quanto maior o número escolhido para a resposta, maior será o seu valor. Assim, estabelece-se que: $(1=1),(2=2),(3=3),(4=4)$ e $(5=5)$. As questões Q3, Q4 e Q26 foram formuladas na direção negativa, logo sua pontuação é invertida ficando da seguinte maneira: $(1=5),(2=4),(3=3),(4=2)$ e $(5=1)$.

Após isso, os resultados finais dos domínios do WHOQOL-Abreviado são obtidos calculando-se a média dos valores de cada domínio. Essa média é multiplicada pelo número 4, uma vez que o instrumento de origem contém quatro questões para cada faceta. Em seguida, os resultados são transfomados em escores de 0 a 100, em operações específicas utilizado-se o programa estatístico SPSS, conforme sua síntese estatística (Anexo D). Esse instrumento não possui um resultado global, os resultados de cada domínio são analisados separadamente.

\section{3 - Análise Estatística}

Os dados obtidos foram apresentados sob a forma de percentual, média e desvio padrão. O nível de significância utilizado foi de 0,05 .

O aplicativo utilizado para a análise estatística foi SPSS nas versões 12.0 e 15.0. Foram, inicialmente, realizadas análises específicas para cada variável, a saber:

- Teste do Qui-quadrado aplicado nas variáveis: sexo, escolaridade, ocupação, motivo da Ampliação Vesical, aparelho para locomoção; 
- Teste exato de Fisher aplicado nas variáveis: relacionamento, religião, tipo de doador, número de transplante, creatinina, medicação imunossupressora, dificuldade de locomoção e renda.

- Teste t-student para as médias: idade, tempo de transplante e domínios do WHOQOL-Abreviado.

- Correlação de Pearson aplicado entre os domínios do WHOQOLAbreviado e suas respectivas facetas e a variável idade.

- Teste Mann-Whitney para o cruzamento das condições com cateterismo e sem cateterismo com o WHOQOL-Abreviado. 


\section{4 - RESULTADOS}

\section{1- População}

Um levantamento prévio dos pacientes transplantados renais com ampliação vesical neste serviço mostrou um total de 38 pacientes com bexiga ampliada, submetidos a transplante renal. No entanto, nem todos os pacientes preencheram os critérios inclusão para participar dessa pesquisa.

A tabela 2 reflete o andamento do estudo de acordo com perda do enxerto ou óbito dos pacientes, no grupo bexiga ampliada. Treze pacientes não foram analisados por perda do enxerto $(n=7)$ ou óbito $(n=6)$. Oito eram menores de 18 anos e foram excluídos

Os restantes 17 pacientes foram abordados. Dois pacientes recusaram-se a participar do estudo, resultando numa população final de 15 pacientes.

Tabela 2 - População final

\begin{tabular}{lr}
\hline \multicolumn{1}{c}{ Ampliação Vesical } & n \\
\hline População Inicial & 38 \\
Perderam o enxerto e/ou foram à óbito & 13 \\
Menores de 18 anos & 8 \\
Recusaram participar & 2 \\
TOTAL & $\mathbf{1 5}$ \\
\hline
\end{tabular}




\section{2 - Caracterização da População}

Conforme a definição do projeto de pesquisa, o estudo foi planejado como caso-controle (1:2) num total de 42 indivíduos, sendo 15 (36\%) Grupo Caso e 27 (64\%) Grupo Controle. Os restantes, 3 pacientes do Grupo Controle não foram conseguidos, na população transplantada, de acordo com os critérios de inclusão para esse grupo.

A tabela 3 apresenta a distribuição demográfica e socioeconômica dos sujeitos. Os grupos foram semelhante em relação à idade, sexo, escolaridade, situação trabalhista, relacionamento e religião.

Na variável escolaridade o número de pacientes com ensino superior no grupo controle é o dobro do percentual no grupo caso (26\% vs $13 \%$ ) sem diferença significativa $(p=0,50)$.

A variável situação trabalhista não apresentou diferença estatística significativa $(p=0,481)$ embora o número de pacientes do grupo caso que são estudantes seja o triplo do grupo controle (13\% vs $4 \%)$.

A variável que apresentou diferença significativa foi Renda Pessoal ( $p=0,013)$. que foi maior no Grupo Controle. 
Tabela 3 - Caracterização demográfica e socioeconômica dos sujeitos

\begin{tabular}{llccc}
\hline & & Caso & Controle & p-valor \\
\hline $\boldsymbol{N}$ & & 15 & 27 & \\
Idade (anos) & Média \pm DP & $36 \pm 14,2$ & $38 \pm 11,1$ & NS \\
Sexo (\%) & Masculino & $9(60)$ & $16(59)$ & NS \\
& Feminino & $6(40)$ & $11(41)$ & \\
& Fundamental & $5(34)$ & $10(37)$ & \\
Escolaridade (\%) & Médio & $8(53)$ & $10(37)$ & NS \\
& Superior & $2(13)$ & $7(26)$ & \\
& Atividade remunerada & $7(47)$ & $16(59)$ & \\
Situação & Aposentado e/ou licença & $6(40)$ & $9(33)$ & NS \\
Trabalhista (\%) & Estudante & $2(13)$ & $1(4)$ & \\
& Desempregado & - & $1(4)$ & \\
Renda Pessoal (\%) & 0 a 1SM & $8(53)$ & $4(15)$ & \multirow{0}{*}{013} \\
& $>$ 1SM & $7(47)$ & $23(85)$ & \\
Relacionamento & Sim & $9(60)$ & $21(77)$ & NS \\
(\%) & Não & $6(40)$ & $6(23)$ & \\
Religião (\%) & Declaram ter & $14(93)$ & $25(92)$ & NS \\
& Declaram não ter & $1(7)$ & $2(8)$ & \\
\hline
\end{tabular}

Nota: $\mathrm{DP}=$ desvio padrão; $\mathrm{NS}=$ não significativo; $\mathrm{SM}$ = salário mínimo

$\mathrm{Na}$ apresentação dos dados do transplante (tabela 4), foram encontradas diferenças significativas entre os grupos nas variáveis tipo de tipo de doador $(p=0,003)$ e número de Transplante $(p=0,035)$. 
Tabela 4 - Dados do transplante

\begin{tabular}{llccc}
\hline & & Caso & Controle & p-valor \\
\hline $\boldsymbol{N}$ & & 15 & 27 & \\
Tipo de Doador (\%) & Vivo & $13(87)$ & $10(37)$ & $\mathbf{0 , 0 0 3}$ \\
& Falecido & $2(13)$ & $17(63)$ & \\
Número de Tx (\%) & Primeiro & $15(100)$ & $19(70)$ & $\mathbf{0 , 0 3 5}$ \\
& Re-Transplante & - & $8(30)$ & \\
Creatinina (mg/dl) & Média \pm DP & $1,44 \pm 0,34$ & $1,39 \pm 0,41$ & NS \\
Tempo Tx (meses) & Média \pm DP & $96 \pm 51,77$ & $103 \pm 42,95$ & NS \\
\hline
\end{tabular}

Nota: DP = desvio padrão; $\mathrm{NS}=$ não significativo; $\mathrm{Tx}=$ transplante

A Tabela 5 revela os imunossupressores utilizados pelos grupos. Conforme o protocolo, os grupos receberam esquemas semelhantes de imunossupressão.

Tabela 5 - Medicação imunossupressora

\begin{tabular}{lccc}
\hline & Caso & Controle & p-valor \\
\hline $\boldsymbol{N}$ & 15 & 27 & \\
Prednisona (\%) & $15(100)$ & $15(100)$ & $\mathrm{NS}$ \\
Azatioprina (\%) & $6(40)$ & $14(52)$ & $\mathrm{NS}$ \\
Rapamicina (\%) & $1(7)$ & - & $\mathrm{NS}$ \\
Micofenolato mofetil & $8(53)$ & $12(44)$ & $\mathrm{NS}$ \\
e sódico (\%) & $5(33)$ & $9(33)$ & $\mathrm{NS}$ \\
Tacrolimus (\%) & $9(60)$ & $16(59)$ & $\mathrm{NS}$ \\
Ciclosporina (\%) & & &
\end{tabular}


No item que diz respeito à locomoção, o Grupo Caso apresentou 5 (33\%) pacientes com dificuldades. Na comparação entre os grupos não foi encontrada diferença significativa $(p=0,077)$.

A Tabela 6 descreve as características específicas da ampliação vesical Três $(20 \%)$ pacientes ampliaram por outros motivos (tuberculose, tumor e capacidade de volume reduzido). Destaca-se ainda, que 10 (67\%) fazem cateterismo. Dos pacientes que têm escapes $5(83,3 \%)$ fazem cateterismo.

Tabela 6 - Dados da ampliação vesical

\begin{tabular}{llcc}
\hline & & AV & p-valor \\
\hline $\boldsymbol{N}$ & & 15 & \\
& Bexiga Neurogênica & $10(67)$ & \\
Motivo (\%) & Extrofia Vesical & $2(13)$ & NS \\
& Outros & $3(20)$ & \\
& Fazem & $10(67)$ & NS \\
Cateterismo (\%) & Não fazem & $5(33)$ & \\
& & $6(40)$ & NS \\
Escapes (\%) & Tem & $9(60)$ & \\
& Não Tem & $2(13)$ & \multirow{2}{*}{ NS } \\
Forros (\%) & Usam & $13(87)$ & \\
& Não usam & $3(20)$ & \\
Aparelho p/ & Ortopédico & $2(13)$ & NS \\
Locomoção (\%) & Cadeira de Rodas & $10(67)$ & \\
& Nenhum &
\end{tabular}

Nota: $\mathrm{NS}=$ não significativo; $\mathrm{AV}=$ ampliação vesical 


\section{3 - Qualidade de Vida}

O WHOQOL - Abreviado é instrumento auto-administrável portanto, a maioria dos pacientes não recebeu ajuda em seu preenchimento. No entanto, dois pacientes não tiveram condições de ler o questionário em função de sua baixa acuidade visual e de alfabetização. A média de tempo de aplicação do questionário foi de aproximandamente 7 minutos.

A tabela 7 apresenta os resultados da comparação dos dois grupos, com os escores obtidos nos domínios: Físico, Psicológico, Relações Sociais e Meio Ambiente.

As médias obtidas em cada domínio pelos dois grupos foram muito próximas. O Domínio Relações Sociais, que demonstra percepção do indivíduo sobre os relacionamentos sociais e os papéis sociais adotados na vida, teve um escore menor no Grupo Caso, embora não atingindo nível de significância estabelecido $(p=0,058)$.

Tabela 7 - Comparação dos grupos com os domínios do WHOQOL-Abreviado

\begin{tabular}{llccc}
\hline \multicolumn{1}{c}{ Domínio } & Valores amostrais & Caso & Controle & p-valor \\
\hline Físico & Média \pm DP & $69,3 \pm 18,8$ & $71,7 \pm 16,03$ & 0,663 \\
Psicológico & Média \pm DP & $77,8 \pm 13,2$ & $78,7 \pm 10,36$ & 0,800 \\
Relações sociais & Média \pm DP & $66,7 \pm 17,3$ & $77,2 \pm 16,45$ & 0,058 \\
Meio ambiente & Média \pm DP & $61,7 \pm 12,8$ & $67,1 \pm 16,02$ & 0,265 \\
\hline
\end{tabular}




\subsection{1 - Questões Gerais}

As questões que avaliam Qualidade de Vida e a satisfação com a saúde, respectivamente questões 1 e 2 , estão descritas na tabela 8 .

Os resultados obtidos não apresentaram diferença significativa na comparação entre os grupos.

Tabela 8 - Comparação dos grupos com as questões gerais

\begin{tabular}{ccccc}
\hline Questões Gerais & Valores amostrais & Caso & Controle & p-valor \\
\hline $\begin{array}{c}\text { Percepção da } \\
\text { Qualidade } \\
\text { de Vida }\end{array}$ & Média \pm DP & $80,0 \pm 16,90$ & $83,3 \pm 13,87$ & NS \\
$\begin{array}{c}\text { Satisfação com a } \\
\text { Saúde }\end{array}$ & Média \pm DP & $86,7 \pm 15,99$ & $80,5 \pm 23,32$ & NS \\
\hline
\end{tabular}

Nota: NS=não significativo

A análise das questões gerais através de suas categorias de respostas demonstrou os resultados semelhantes da tabela anterior.

O enunciado da questão 1 era: "Como você avaliaria sua qualidade de vida?"

Baseado no enunciado, oito (54\%) pacientes do Grupo Caso consideraram sua Qualidade de Vida “boa” e 5 (33\%) consideraram-na “muito boa”, conforme tabela 9. No Grupo controle, 16 (59\%) consideraram-na “boa” e 10 (37\%) “muito boa”.

Os Demais pacientes não definiram nem como boa nem como ruim sua Qualidade de Vida. 
Tabela 9 - Respostas categóricas da questão 1

\begin{tabular}{llcc}
\hline & & Caso & Controle \\
\hline $\boldsymbol{N}$ & & 15 & 27 \\
Avaliação da & Nem ruim nem boa & $2(13)$ & $1(4)$ \\
Qualidade de Vida (\%) & Boa & $8(54)$ & $16(59)$ \\
& Muito boa & $5(33)$ & $10(37)$ \\
\hline
\end{tabular}

$\boldsymbol{p}=0,527$

A questão 2 tinha por enunciado: "Quão satisfeito (a) você está com a sua saúde?”.

A tabela 10 demonstra a equiparação de respostas entre os grupos.

Tabela 10 - Respostas categóricas da questão 2

\begin{tabular}{llcc}
\hline & & Caso & Controle \\
\hline $\boldsymbol{N}$ & & 15 & 27 \\
& Muito insatisfeito & - & $1(4)$ \\
& Insatisfeito & - & $1(4)$ \\
Satisfação com & Nem satisfeito nem insatisfeito & $1(7)$ & $2(7)$ \\
a Saúde (\%) & Satisfeito & $6(40)$ & $10(37)$ \\
& Muito satisfeito & $8(53)$ & $13(48)$ \\
\hline $\boldsymbol{p}=0,764$ & & &
\end{tabular}

\subsection{2 - Correlação entre os Domínios do WHOQOL-Abreviado e suas facetas}

A partir dos resultados obtidos com o WHOQOL-Abreviado buscou-se identificar as facetas que mais influenciaram no escore da Qualidade de Vida em cada um dos domínios do instrumento. Para isso correlacionou-se o escore médio de 
cada domínio com as questões que o compõe. A análise foi feita em separado por grupo.

\subsubsection{1 - Correlação com Domínio Físico}

Este domínio mostra a percepção do indivíduo sobre sua condição física. As atividades da vida geralmente se referem aos cuidados básicos de higiene pessoal e tarefas de auto-cuidado (banhar-se, arrumar-se, locomover-se), associado com tarefas mais complexas que são desempenhadas no dia-a-dia (administração das finanças e medicamentos, utilização do telefone, compras necessárias, preparação da refeição, uso de transporte e desempenho básico na arrumação de casa.

No Grupo Controle não se encontrou nenhuma correlação entre o escore médio do domínio e suas facetas. Com isso, inferiu-se que todas as facetas, contribuíram de igual maneira para o resultado deste domínio para esse grupo (tabela 11).

Para o Grupo Caso, apenas a faceta dependência de medicação ou tratamento, que significa o quanto o paciente necessita de algum tratamento médico para levar a sua vida diária, não apresentou correlação significativa com o escore médio do Domínio Físico.

A faceta dor e desconforto, cujo significado é o quanto o paciente percebe que a dor (física) o impede de fazer o que precisa em sua vida cotidiana, apresentou correlação negativa significante com o escore médio do Domínio Físico, ou seja, quanto maior a dor física, menor foi o escore obtido neste domínio. Nessa faceta, $4(26,7 \%)$ indivíduos entenderam que sua dor física os impediria "bastante" de realizar suas atividades cotidianas. 
A faceta energia e fadiga, que quer saber se o paciente tem energia suficiente para fazer o que precisa em seu dia-a-dia, apresentou correlação significativa com o escore médio do Domínio Físico. Ou seja, quanto mais energia o paciente tem para realizar o que precisa cotidianamente, maior será o escore médio desse domínio. Quanto às respostas apresentadas, $9(60 \%)$ dos pacientes disseram ter “muito" ou "completamente" energia para realizarem o que necessitam.

A correlação do escore médio do Domínio Físico com a faceta mobilidade que significa capacidade de locomoção foi significante, isto é, quanto maior a capacidade de locomoção do paciente, maior foi o escore médio nesse do domínio. Nessa faceta, $11(73,3 \%)$ responderam “bom” e "muito bom” quando perguntado o "Quão bem você é capaz de se locomover?”

A faceta atividade de vida cotidiana significa a satisfação que o indivíduo tem com sua capacidade para desenvolver atividades diárias (banhar-se, arrumar-se, administrar suas finanças, realizar compras, preparar refeições, etc), apresentou correlação estatisticamente significante com o escore médio desse domínio. Onze $(73,3 \%)$ disseram estar "satisfeitos" ou "muito satisfeitos" com sua capacidade para desempenhar as atividades diárias. Falando em termos de correlação, quanto maior a satisfação com o seu desempenho nas atividades diárias, maior o escore médio do Domínio Físico.

A correlação entre o escore médio do Domínio Físico com a faceta sono e repouso foi positiva e estatisticamente significante. Quanto mais satisfeito o paciente respondeu estar com seu sono, maior foi o escore médio do domínio. Onze $(73,3 \%)$ dos indivíduos responderam estar "satisfeitos" ou "muito satisfeitos” com seu sono. 
A faceta capacidade de trabalho que apura o quanto o indivíduo está satisfeito com seu desempenho em realizar as atividades referentes ao seu trabalho, está significativamente correlacionado com o escore médio do Domínio Físico. Isto quer dizer que quanto maior a capacidade de trabalho, maior foi o escore médio do domínio. Ressalta-se ainda, que $11(73,4 \%)$ dos pacientes desse grupo responderam estar "satisfeitos" ou "muito satisfeitos" com sua capacidade de trabalho.

Tabela 11 - Correlação entre as facetas e o domínio físico de acordo com o grupo

\begin{tabular}{|c|c|c|c|c|c|}
\hline Questão & Faceta & CASO & & CONTF & \\
\hline & & $\begin{array}{l}\text { Correlação } \\
\text { IC } 95 \%\end{array}$ & $p$-valor & $\begin{array}{c}\text { Correlação } \\
\text { IC 95\% }\end{array}$ & $p$-valor \\
\hline 3 & $\begin{array}{c}\text { Dor e } \\
\text { desconforto }\end{array}$ & $\begin{array}{c}(0,703) \\
{[-0,893 ;-0,298]}\end{array}$ & 0,004 & $\begin{array}{c}(0,302) \\
{[-0,612 ; 0,088]}\end{array}$ & 0,126 \\
\hline 4 & $\begin{array}{l}\text { Dependência de } \\
\text { medicação ou de } \\
\text { tratamento }\end{array}$ & $\begin{array}{c}(0,337) \\
{[-0,724 ; 0,212]}\end{array}$ & 0,220 & $\begin{array}{c}(0,055) \\
{[-0,427 ; 0,332]}\end{array}$ & 0,784 \\
\hline 10 & Energia e fadiga & $\begin{array}{c}0,838 \\
{[0,570 ; 0,945]}\end{array}$ & $<0,001$ & $\begin{array}{c}0,100 \\
{[-0,292 ; 0,462]}\end{array}$ & 0,621 \\
\hline 15 & Mobilidade & $\begin{array}{c}0,821 \\
{[0,532 ; 0,938]}\end{array}$ & $<0,001$ & $\begin{array}{c}0,257 \\
{[-0,136 ; 0,581]}\end{array}$ & 0,257 \\
\hline 16 & Sono e repouso & $\begin{array}{c}0,614 \\
{[0,149 ; 0,857]}\end{array}$ & 0,015 & $\begin{array}{c}(0,174) \\
{[-0,520 ; 0,221]}\end{array}$ & 0,385 \\
\hline 17 & $\begin{array}{l}\text { Atividades de } \\
\text { vida cotidiana }\end{array}$ & $\begin{array}{c}0,875 \\
{[0656 ; 0,958]}\end{array}$ & $<0,001$ & $\begin{array}{c}0,136 \\
{[-0,258 ; 0,490]}\end{array}$ & 0,500 \\
\hline 18 & $\begin{array}{l}\text { Capacidade de } \\
\text { trabalho }\end{array}$ & $\begin{array}{c}0,881 \\
{[0,673 ; 0,960]}\end{array}$ & $<0,001$ & $\begin{array}{c}0,121 \\
{[-0,271 ; 0,479]}\end{array}$ & 0,546 \\
\hline
\end{tabular}




\subsubsection{2 - Correlação com Domínio Psicológico}

O Domínio Psicológico apura a percepção do indivíduo sobre sua condição afetiva e congnitiva. Ou seja, representa o grau de sua satisfação com a vida. Engloba a avaliação de aspectos emocionais como: humor e sentimentos envolvidos tanto na situação da doença como na condição da Qualidade de Vida.

A tabela 12 apresenta as correlações das facetas com o escore médio do Domínio Psicológico, para os dois grupos.

No Grupo Controle não se encontrou nenhuma correlação entre o escore médio do domínio e suas facetas. Com isso, inferiu-se que todas as facetas, contribuíram de igual maneira para o resultado deste domínio para esse grupo.

No Grupo Caso, algumas correlações foram encontradas.

A faceta sentimentos positivos, que significa o quanto o indivíduo aproveita sua vida, demonstrou estar correlacionada com o escore médio do Domínio Psicológico e é estatisticamente significante. Assim, quanto mais o paciente considera que aproveita sua vida, maior foi o escore médio desse domínio. Nove (73,4\%) pacientes responderam que aproveitam "bastante" ou "extremamente" a vida.

A faceta espiritualidade/religião/crenças pessoais, que significa o quanto o indivíduo acha que sua vida tem sentido, apresentou correlação positiva e significante. Ou seja, quanto mais o paciente acha que sua vida tem sentido, maior foi o valor do escore médio do Domínio Psicológico. As respostas “bastante” ou "extremamente" foram escolhidas por $11(80 \%)$ pacientes para designar o quanto acham que sua vida tem sentido. 
A correlação entre o escore médio do Domínio Psicológico e a faceta imagem corporal, que significa o quanto o indivíduo aceita sua aparência, foi estatisticamente significante. Quanto maior a aceitação do paciente com sua imagem corporal, maior foi o escore médio desse domínio. Doze $(80 \%)$ dos pacientes responderam que aceitam “muito” ou “completamente” sua aparência física.

A faceta auto-estima apura o quanto o indivíduo está satisfeito consigo mesmo, apresentou correlação positiva e significante com o escore médio do Domínio Psicológico. Quanto mais satisfeitos consigo mesmo, maior foi o escore médio desse domínio. "Satisfeitos" ou "muito satisfeitos" foram as respostas dadas por $13(86,7 \%)$ dos pacientes para designar sua satisfação consigo mesmo.

Tabela 12 - Correlação entre as facetas e o domínio psicológico de acordo com o grupo

\begin{tabular}{|c|c|c|c|c|c|}
\hline Questão & Faceta & CASO & & CONTRC & $\mathbf{E}$ \\
\hline & & $\begin{array}{c}\text { Correlação } \\
\text { IC 95\% }\end{array}$ & p-valor & $\begin{array}{c}\text { Correlação } \\
\text { IC 95\% }\end{array}$ & p-valor \\
\hline 5 & Sentimentos positivos & $\begin{array}{c}0,684 \\
{[0,265 ; 0,886]}\end{array}$ & 0,005 & $\begin{array}{c}0,190 \\
{[-0,205 ; 0,532]}\end{array}$ & 0,342 \\
\hline 6 & $\begin{array}{l}\text { Espiritualidade/religião/ } \\
\text { crenças pessoais }\end{array}$ & $\begin{array}{c}0,686 \\
{[0,269 ; 0,887]}\end{array}$ & 0,005 & $\begin{array}{c}0,277 \\
{[-0,116 ; 0,594]}\end{array}$ & 0,163 \\
\hline 7 & $\begin{array}{c}\text { Pensar, aprender, } \\
\text { memória e concentração }\end{array}$ & $\begin{array}{c}0,497 \\
{[-0,020 ; 0,805]}\end{array}$ & 0,059 & $\begin{array}{c}0,203 \\
{[-0,192 ; 0,541]}\end{array}$ & 0,311 \\
\hline 11 & $\begin{array}{c}\text { Imagem corporal e } \\
\text { aparência }\end{array}$ & $\begin{array}{c}0,868 \\
{[0,640 ; 0,955]}\end{array}$ & $<0,001$ & $\begin{array}{c}(0,223) \\
{[-0,556 ; 0,171]}\end{array}$ & 0,263 \\
\hline 19 & Auto-estima & $\begin{array}{c}0,746 \\
{[0,378 ; 0,910]}\end{array}$ & 0,001 & $\begin{array}{c}0,119 \\
{[-0,273 ; 0,478]}\end{array}$ & 0,554 \\
\hline 26 & Sentimentos negativos & $\begin{array}{c}(0,290) \\
{[-0,699 ; 0,261]}\end{array}$ & 0,294 & $\begin{array}{c}0,170 \\
{[-0,224 ; 0,517]}\end{array}$ & 0,396 \\
\hline
\end{tabular}




\subsubsection{3 - Correlação com Relações Sociais}

O Domínio Relações Sociais apura a percepção do indivíduo sobre os relacionamentos sociais e os papéis sociais adotados na vida. Ou ainda, são dimensões de bem-estar do indivíduo que considera a maneira como ele interage com as pessoas do seu meio social, de como essas pessoas reagem a ele, e ainda, quais os tipos de relação que ele estabeleceu com as instituições sociais.

A tabela 13 apresenta as correlações do escore médio do Domínio Relações Sociais com suas facetas, para o Grupo Caso e para o Grupo Controle.

Em ambos os grupos a faceta relações pessoais apresentou correlação com o Domínio Relações Sociais.. Esta faceta que aponta a satisfação do indivíduo com suas relações pessoais (amigos, parentes, conhecidos, colegas, etc) apresentou correlação positiva e significante com o escore médio do Domínio Relações Sociais. Isso quer dizer que quanto mais satisfeito com suas relações pessoais, maior seu escore médio para o domínio em referência

As demais facetas somente correlacionaram-se com o Domínio no Grupo Caso.

A faceta atividade sexual, que significa o quão satisfeito o indivíduo está com sua vida sexual, apresentou correlação estatisticamente significante com o escore médiodo Domínio Relações Sociais. Oito $(53,3 \%)$ pacientes declaram estar “satisfeitos” ou "muito satisfeitos” com sua vida sexual. Isso quer dizer que quanto maior a satisfação do paciente com sua vida sexual, maior o escore médio do domínio.

A correlação do escore médio do Domínio Relações Sociais com a faceta suporte (apoio) social, que apura o quão satisfeito o indivíduo está com o apoio que 
recebe de seus amigos, foi significante. Portanto, quanto maior a satisfação com o apoio recebido dos amigos, maior foi o escore médio do domínio em referência. "Satisfeitos” ou "muito satisfeitos" foram as respostas dadas por 6 (40\%) dos pacientes para designar sua satisfação com o apoio recebido dos amigos.

No Grupo Controle a única faceta que foi correlacionada e estatisticamente significante com o escore médio do Domínio Relações Sociais foi relações pessoais. Esta faceta apura a satisfação do indivíduo com suas relações pessoais. Vinte e quatro $(88,8 \%)$ dos pacientes responderam estar "satisfeitos" ou “muito satisfeitos” com suas relações pessoais, Ou seja, quanto maior o grau de satisfação com suas relações pessoais, maior foi o escore médio do Domínio Relações Sociais para esse grupo.

Tabela 13 - Correlação entre as facetas e o domínio relações social de acordo com o grupo

\begin{tabular}{|c|c|c|c|c|c|}
\hline \multirow[t]{2}{*}{ Questão } & \multirow[t]{2}{*}{ Faceta } & \multicolumn{2}{|c|}{ CASO } & \multicolumn{2}{|c|}{ CONTROLE } \\
\hline & & $\begin{array}{c}\text { Correlação } \\
\text { IC 95\% }\end{array}$ & p-valor & $\begin{array}{c}\text { Correlação } \\
\text { IC 95\% }\end{array}$ & p-valor \\
\hline 20 & Relações pessoais & $\begin{array}{c}0,776 \\
{[0,438 ; 0,922]}\end{array}$ & $<0,001$ & $\begin{array}{c}0,450 \\
{[0,085 ; 0,709]}\end{array}$ & 0,019 \\
\hline 21 & Atividade sexual & $\begin{array}{c}0,781 \\
{[0,448 ; 0,924]}\end{array}$ & $<0,001$ & $\begin{array}{c}0,147 \\
{[-0,247 ; 0,499]}\end{array}$ & 0,465 \\
\hline 22 & Suporte (apoio) social & $\begin{array}{c}0,703 \\
{[0,298 ; 0,894]}\end{array}$ & 0,004 & $\begin{array}{c}0,062 \\
{[-0,325 ; 0,432]}\end{array}$ & 0,757 \\
\hline
\end{tabular}




\subsubsection{4 - Correlação com Domínio Meio Ambiente}

O Domínio Meio Ambiente mostra a percepção do indivícuo sobre diversos aspectos relacionados ao ambiente onde vive, levando em conta a infraestrutura desse ambiente.

A tabela 14 mostra a correlação entre o escore médio do Domínio Relações Sociais com suas facetas.

No Grupo Controle não se encontrou nenhuma correlação entre o escore médio do domínio e suas facetas. Com isso, inferiu-se que todas as facetas, contribuíram de igual maneira para o resultado deste domínio para esse grupo.

No Grupo Caso, algumas correlações foram encontradas.

A faceta segurança e proteção, que significa o quão seguro o indivíduo se sente em sua vida daria, apresentou correlação estatisticamente significativa com o escore médio do domínio acima referido. Ou seja, quanto mais seguro o paciente se sente em sua vida diária, maior o escore médio do Domínio Meio Ambiente. Com relação às respostas dadas pelos respondentes, $9(60 \%)$ dos pacientes disseram sentirem-se "bastante” ou “extremamente” seguros quanto à sua vida diária.

A faceta recursos financeiros que apura o quão satisfeito o indivíduo está com o dinheiro que tem para suas necessidades, foi significativamente correlacionado com o escore médio do Domínio Meio Ambiente. Portanto, quanto maior a satisfação com quantidade de dinheiro para utilizar em suas necessidades, maior foi o escore médio para esse domínio. Nove $(60 \%)$ dos pacientes responderam que estão "bastante" ou "extremamente" satisfeito com o quantum de dinheiro para suas necessidades diárias. 
A correlação entre o escore médio do Domínio Meio Ambiente e a faceta oportunidades de adquirir novas informações e habilidades, que significa o quão disponíveis estão as informações que o indivíduo precisa para o seu dia-a-dia, foi estatisticamente significante. Quanto maior a disponibilidade de informações que o paciente tem diariamente maior o escore médio do domínio. Oito $(53,3 \%)$ dos pacientes responderam ter "médias" oportunidades de adquirir informações diariamente.

A faceta participação em, e oportunidades de recreação/lazer, que apura o quanto de oportunidades de lazer o indivíduo tem, apresentou correlação significante com o escore médio do Domínio Meio Ambiente. Isso implica que quanto mais oportunidades de lazer o paciente, tem maior o escore médio do domínio em referência. "Muito" ou "completamente" foram as respostas dadas por $9(60 \%)$ dos pacientes para a questão: "Em que medida você tem oportunidades de atividade de lazer?”

Cuidados de saúde e sociais: disponibilidade e qualidade, foi mais uma faceta correlacionada significativamente com o escore médio do Domínio Meio Ambiente. Essa faceta mostra o quão satisfeito o indivíduo está com o seu acesso aos serviços de saúde. Dez (66,7\%) dos pacientes responderam estar "satisfeitos" ou “muito satisfeitos” com seu acesso aos serviços de saúde. Portanto, quanto maior o grau de satisfação com o acesso aos serviços de saúde, maior foi o escore médio desse domínio. 
Tabela 14 - Correlação entre as facetas e o domínio meio ambiente de acordo com o grupo

\begin{tabular}{|c|c|c|c|c|c|}
\hline \multirow[t]{2}{*}{ Questão } & \multirow[t]{2}{*}{ Faceta } & \multicolumn{2}{|l|}{ CASO } & \multicolumn{2}{|c|}{ CONTROLE } \\
\hline & & $\begin{array}{c}\text { Correlação } \\
\text { IC } 95 \%\end{array}$ & p-valor & $\begin{array}{c}\text { Correlação } \\
\text { IC 95\% }\end{array}$ & p-valor \\
\hline 8 & Segurança física e proteção & $\begin{array}{c}0,809 \\
{[0,507 ; 0,934]}\end{array}$ & $<0,001$ & $\begin{array}{c}0,168 \\
{[-0,227 ; 0,515]}\end{array}$ & 0,404 \\
\hline 9 & Ambiente no lar & $\begin{array}{c}(0,013) \\
{[0,522 ; 0,502]}\end{array}$ & 0,963 & $\begin{array}{c}-0,044 \\
{[-0,417 ; 0,342]}\end{array}$ & 0,828 \\
\hline 12 & Recursos financeiros & $\begin{array}{c}0,597 \\
{[0,123 ; 0,850]}\end{array}$ & 0,019 & $\begin{array}{c}0,141 \\
{[-0,253 ; 0,494]}\end{array}$ & 0,484 \\
\hline 13 & $\begin{array}{c}\text { Oportunidades de adquirir } \\
\text { novas informações e } \\
\text { habilidades }\end{array}$ & $\begin{array}{c}0,769 \\
{[0,425 ; 0,920]}\end{array}$ & $<0,001$ & $\begin{array}{c}0,009 \\
{[-0,372 ; 0,388]}\end{array}$ & 0,963 \\
\hline 14 & $\begin{array}{l}\text { Participação em, e } \\
\text { oportunidades de } \\
\text { recreação/lazer }\end{array}$ & $\begin{array}{c}0,648 \\
{[0,203 ; 0,871]}\end{array}$ & 0,009 & $\begin{array}{c}0,020 \\
{[-0,363 ; 0,397]}\end{array}$ & 0,921 \\
\hline 23 & $\begin{array}{c}\text { Ambiente físico } \\
\text { (poluição/ruído/trânsito/clima) }\end{array}$ & $\begin{array}{c}0,347 \\
{[-0,201 ; 0,730]}\end{array}$ & 0,205 & $\begin{array}{c}(0,034) \\
{[-0,409 ; 0,351]}\end{array}$ & 0,868 \\
\hline 24 & $\begin{array}{l}\text { Cuidados de saúde e sociais: } \\
\text { disponibilidade e qualidade }\end{array}$ & $\begin{array}{c}0,614 \\
{[0,148 ; 0,857]}\end{array}$ & 0,015 & $\begin{array}{c}(0,069) \\
{[-0,437 ; 0,320]}\end{array}$ & 0,734 \\
\hline 25 & Transporte & $\begin{array}{c}0,408 \\
{[-0,131 ; 0,762]}\end{array}$ & 0,130 & $\begin{array}{c}(0,023) \\
{[-0,399 ; 0,361]}\end{array}$ & 0,911 \\
\hline
\end{tabular}

\subsection{3 - Outras Correlações}

Outros resultados foram obtidos a partir da correlação da variável demográficas Idade com o escore médio dos domínios e questões gerais do WHOQOL-Abreviado.

As correlações foram feitas para o Grupo Caso e Grupo Controle, mas apenas no segundo grupo elas ocorreram.

A variável Idade correlacionou-se com a Questão Geral que aponta a Percepção da Qualidade de Vida, apresentando $\mathrm{r}=(0,495)$ e $p=0,009$. Tal correlação 
indica que quanto maior a idade do paciente, menor foi sua Percepção de Qualidade de Vida.

Outra correlação encontrada foi Idade x Domínio Físico que apurou um $\mathrm{r}=(0,439)$ e $p=0,022$, indicando que quanto maior a idade, menor o escore médio do Domínio Físico.

A variável idade também se correlacionou com o escore médio do Domínio Psicológico obtendo um $\mathrm{r}=(0,406)$ e $p=0,036$. Ou seja, quanto maior a idade, menor foi o escore do Domínio Psicológico.

A correlação entre a variável Idade com o escore médio do Domínio Relações Sociais apurou um $\mathrm{r}=(0,451)$ e $p=0,018$. Tal resultado demonstra que quanto maior a idade do paciente, menor foi o valor obtido no Domínio Relações Sociais.

\subsection{4 - Outros Resultados}

Pelo Grupo Caso ser composto de pacientes que fazem cateterismo intermitente, achou-se importante verificar se havia diferença na Qualidade de Vida entre os pacientes que fazem cateterismo e os que não fazem.

Não foi encontrada diferença significativa para os grupos conforme demonstrado abaixo:

1. Questão Geral Qualidade de Vida - a média da questão obtida pelos pacientes com cateterismo foi de 82,5 e sem cateterismo de $75,0(p=0,415)$

2. Questão Geral Saúde - a média da questão obtida pelos pacientes com cateterismo foi de 90,0 e sem cateterismo de $80,0(p=0,334)$; 
3. Domínio Físico - a média do domínio obtida pelos pacientes com cateterismo foi de 65,0 e sem cateterismo de 77,9 $(p=0,268)$;

4. Domínio Psicológico - a média do domínio obtida pelos pacientes com cateterismo foi de 76,2 e sem cateterismo de 80,8 ( $p>0,999)$;

5. Domínio Relações Sociais - a média obtida pelos pacientes com cateterismo foi de 66,6 e sem cateterismo de $66,7(p=0,950)$;

6. Domínio Meio Ambiente - a média do domínio obtida pelos pacientes com cateterismo foi de 63,7 e sem cateterismo de 57,5 $(p=0,462)$.

Isso quer dizer que a percepção de Qualidade de Vida dos pacientes do Grupo Caso não é diferente entre os pacientes que fazem e os que não fazem cateterismo. 


\section{5 - DISCUSSÃO}

\section{1 - Aspectos Gerais}

Os pacientes com Ampliação Vesical formam um subgrupo muito específico dentre os transplantados renais.

Anteriormente, indivíduos com ampliação Vesical não eram transplantados, pois o esvaziamento da bexiga em muitos casos não ocorria satisfatoriamente causando refluxo vesicoureteral e conseqüentemente a perda do enxerto e/ou a morte do paciente. Os transplantes renais que foram realizados com segmento ileal não foram bem sucedidos (65).

A primeira cistoplastia após o transplante renal foi relatada em 1982 (66) e, em 1984 ocorreu o primeiro transplante renal pediátrico em bexiga ampliada drenada (67).

A população pediátrica tem uma incidência de 20 a 30\% de IRCT devido as disfunções urinárias Várias são as causas de anormalidades vesicais, no entanto, a mielomeningocele e as válvulas ureterais posteriores são as mais comuns em crianças com IRCT $(68,69)$.

Com ao advento do cateterismo limpo (54), novas possibilidades surgiram para os pacientes com Ampliação Vesical sem um completo esvaziamento vesical $(61,70)$. No entanto, pacientes que são submetidos à Ampliação Vesical podem apresentar dificuldades de ordem física que podem refletir em sua vida psicológica e nas interações sociais (54). As dificuldades não seriam apenas físicas, mas também psicológicas (71) e sociais (72), fatores que interferem também em uma 
boa Qualidade de Vida. Por este motivo, um estudo sobre a Qualidade de Vida destes pacientes parecia necessário.

No entanto, um fator limitante no poder do resultado final seria o número de pacientes passíveis de ser avaliados. A Unidade de Transplante Renal da Divisão de Clínica Urológica do Instituo Central do Hospital das Clínicas da Faculdade de Medicina da Universidade de São Paulo possui uma das maiores casuísticas de ampliados vesicais transplantados. Nos últimos vinte anos, 25 crianças submeteramse a este procedimento recebendo 28 enxertos renais. No entanto, somente 15 pacientes estavam disponíveis no momento da avaliação, embora esta casuística seja muito razoável comparada a outros estudos onde o número de sujeitos é sempre muito pequeno $(69,73-82)$.. Alem disso, o número estudado representa toda a população destes pacientes e não uma amostra dela, representando um número expressivo em vista da baixa incidência de casos na população transplantada em qualquer centro do mundo.

Estabelecido o Grupo Caso, faltava saber com quem comparar esses pacientes e que instrumento utilizar para essa avaliação. O pareamento da população de ampliados vesicais transplantados com pacientes transplantados sem ampliação vesical pareceu lógico. Outra possibilidade seria comparar com a população geral.pegar indivíduos da população geral, estabelecer parâmetros para a escolha e realizar o estudo. No entanto, a escolha dessa população traria algumas dificuldades de ordem prática.. Além disso, o Grupo Controle precisava ser pareado para outros fatores que interferem com a Qualidade de vida, como receber imunosupressores, por exemplo, e as condições de uma população geral seriam muito dispares das condições dos pacientes do estudo. Alem disso, os estudos que comparam a 
população transplantada com a população geral já mostram uma inferioridade nos transplantados. O efeito específico da Ampliação vesical com cateterismo vesical intermitente seria perdido entre outros fatores.

Na literatura encontramos estudos comparativos que avaliam a Qualidade de Vida de pessoas transplantadas com a população geral (51). O pareamento da população de ampliados vesicais transplantados com pacientes transplantados pareceu mais lógica, além de oferecer maior contribuição à comunidade científica, uma vez que não havia estudos com essa população específica.

Outro aspecto foi a escolha do instrumento que seria usado para a avaliação da Qualidade de Vida.

Dois instrumentos poderiam ser usados para esse estudo, o SF-36 (83, 84) e o WHOQOL-Abreviado.

Ambos os instrumentos são conhecidos e utilizados na Nefrologia (85, 86), são de fácil aplicação, são multidimensional, ou seja, abordam vários aspectos da vida do indivíduo. No entanto, a perspectiva na qual Qualidade de Vida é apurada nos dois instrumentos é diferente.

O SF-36 é um questionário que avalia a Qualidade de Vida relacionada à saúde. Ou seja, a medida de Qualidade de Vida está relacionada ao estado de saúde. Suas questões são voltadas para a percepção do paciente sobre sua Qualidade de Vida, mas o enfoque dessas questões fica no âmbito físico, funcional e sintomatológico. Até mesmo a questão que enfoca aspectos emocionais parte da perspectiva funcional. Quando o foco fica em aspectos tão concretos uma avaliação subjetiva fica prejudica. 
O WHOQOL-Abreviado é um instrumento que avalia a Qualidade de Vida geral. O enfoque para responder as questões é a vida e os aspectos que a envolve e não somente aos aspectos relacionados à saúde (12). O ponto de partida para as respostas é a subjetividade.

A definição de Qualidade de Vida escolhida como norteadora desse estudo foi da OMS e o WHOQOL é o instrumento criado pela organização tendo como base essa definição. Achou-se então, que seria ele o que daria a mais adequada resposta de Qualidade de Vida para esse estudo.

Além do que, na área de formação da pesquisadora os objetos de estudo são o indivíduo e sua subjetividade.

Por estas razões é o WHOQOL-Abreviado foi o escolhido para esse estudo.

O instrumento foi aplicado um tempo único e a princípio não se entendeu que isso inviabilize a análise dos resultado. Vários estudos foram realizados aplicando o instrumento em tempo único $(43,50-52)$.

\section{2 - Qualidade de Vida}

Diante desse quadro, os resultados obtidos neste estudo a partir da avaliação da Qualidade de Vida do paciente transplantado renal submetido à ampliação vesical surpreenderam.

Ao iniciar-se esse estudo partiu-se da concepção de que pacientes transplantados renais com ampliação vesical, particularmente sob cateterismo intermitente, teriam uma Qualidade de Vida pior se comparados com outros pacientes transplantados renais. 
Esperava-se que a comparação entre os dois grupos de transplantados renais, com e sem ampliação vesical, revelasse uma diferença nos domínios físico, psicológico e relações sociais. No entanto, o único domínio que expressou uma diferença na comparação dos grupos foi o Domínio Relações Sociais.

Os grupos foram bastante homogêneos, como esperado pelo processo de escolha do grupo controle com exceção da variável Renda Pessoal.

Uma explicação possível para a diferença da variável Renda Pessoal pode estar ligada a uma inserção tardia ao mercado de trabalho e mão-de-obra não qualificada. Pacientes com doença crônica de infância necessitam desde cedo de tratamentos prolongados (87) e longos períodos de internação que podem ter promovido uma inserção tardia na vida escolar. Podem ter ocorrido ainda, grandes interrupções no processo de aprendizado formal e em alguns casos o abandono escolar foi uma realidade (88). Isso acarretaria na não qualificação do paciente e numa baixa remuneração.

Os resultados desse estudo expressam uma diferença na Qualidade de Vida dos pacientes transplantados renais submetidos à ampliação vesical.

Como já foi dito, esperava-se encontrar diferenças nos Domínios Físico, Psicológico e Relações Sociais, no entanto, ela foi encontrada apenas no Domínio Relações Sociais.

Este domínio apura a percepção do paciente sobre os relacionamentos sociais e os papéis sociais adotados na vida. Ou ainda, são dimensões de bem-estar do indivíduo que considera a maneira como ele interage com as pessoas do seu meio social, de como essas pessoas reagem a ele, e ainda, quais os tipos de relação que ele 
estabeleceu com as instituições sociais. Engloba as facetas: relações pessoais; suporte (apoio) social; atividade sexual (20).

Esse resultado não pode ser confrontado com a literatura uma vez que não foram encontrados estudos utilizando o WHOQOL para avaliar a Qualidade de Vida em população de ampliados vesicais transplantados ou não. No entanto, podemos pensar em algumas possibilidades para o Grupo Caso ter uma Qualidade de Vida menor no Domínio Relações Sociais.

A maioria dos pacientes desse estudo são portadores de bexiga neurogênica congênita e extrofia vesical, doenças crônicas da infância. A doença crônica é caracteriza por seu curso demorado, por sua evolução progressiva e a necessidade de tratamentos prolongados (87) provocando impacto na capacidade funcional da criança. E, mesmo diante da evolução dos tratamentos, a criança necessita passar por procedimentos médicos invasivos e longos períodos de hospitalização. Esses fatores podem afetar o desenvolvimento físico da criança que pode apresentar, por conta disso, desajustes psicológicos decorrentes da enfermidade e do tratamento (89). Essas dificuldades podem ser minimizadas a partir do apoio social, que tem o efeito na prevenção de perturbações psicológicas e orgânicas quando o indivíduo se vê diante de situações estressantes, na diminuição da gravidade da doença e na recuperação delas $(72,90)$.

O apoio social deve ser compreendido como uma experiência pessoal e reconhecido como papel de apoio da intensidade com que o indivíduo se sente desejado, respeitado e envolvido (72). Autores sugerem que o apoio social pode agir diretamente na saúde, na adaptação psicológica e na percepção de bem-estar (91-93). A importância do apoio social foi configurada na correlação da faceta suporte (apoio) 
social com o Domínio Relações Sociais. Essa correlação aponta para uma influência direta da faceta para o resultado final do domínio.

É importante ressaltar que ter influenciado no resultado do domínio não quer dizer que a Qualidade de Vida tenha sido melhor. E, nesse caso em específico, o que a correlação demonstrou é que esses pacientes têm uma dependência muito maior do suporte social do que os pacientes do outro grupo.

Isso se explica novamente pelas características da patologia crônica de infância que afetam as interações com todas as instâncias sociais.

Entende-se que em algum momento pode ter havido uma falha no suporte dado pela primeira instituição social, a família. Essa falha pode ter ocorrido não porque os pais tinham desinteresse em seus filhos, mas porque a doença crônica é vista como um estressor que afeta o desenvolvimento normal da criança e atinge também as relações sociais dentro do sistema familiar (89).

O hospital, representado pela equipe de saúde (médico, enfermeiro, auxiliar, psicólogo e assistente social) também constitui outra instituição de suporte social. E, em algum momento ela também pode ter falhado no suporte dado a esses pacientes. Não que o suporte não existisse, mas pode não ter sido efetivo e eficaz por não haver parâmetros que comprovassem sua eficácia e alcance.

Uma informação que nasce desta investigação é que, talvez, deva caber ao psicólogo a promoção de grupos de discussão com temas específicos ou ainda o levantamento das dificuldades encontradas por esses pacientes e seus familiares não apenas no âmbito clínico/hospitalar. Ou ainda, talvez grupos de familiares para discutirem as dificuldades que a doença crônica traz para o núcleo familiar, 
Outro aspecto que influenciou o resultado do Domínio Relações Sociais foi atividade sexual característica deste grupo de indivíduos. Novamente deve-se ressaltar que esse resultado demonstra uma dependência ou desajuste nesse aspecto freqüentemente impossível de ser resolvido, mas que pode ser trabalhado. Outra característica com relação à sexualidade muito importante desse grupo, é o fato de existirem indivíduos com meningomielocele. Esses indivíduos são impotentes e no caso das mulheres não tem sensibilidade genital.

Fica difícil pensar em atividade sexual apenas como um aspecto interacional e que diz respeito apenas ao âmbito das relações sociais. Entende-se sexualidade pertencente e ligada aos aspectos psicológicos do indivíduo. A sexualidade está altamente ligada à imagem corporal (94), por essa razão a discussão se dará juntamente com o Domínio Psicológico.

O Domínio Psicológico aponta para a condição afetiva e cognitiva e pode dar algumas pistas de como o paciente ampliado vesical transplantado está satisfeito ou não com sua vida. Algumas facetas tiveram maior influência no resultado final do domínio, são elas: sentimentos positivos, espiritualidade/religião/crenças pessoais, imagem corporal e auto-estima. O comportamento dos dois grupos foi diferente nesse domínio. Esse estudo não consegue responder o motivo dessa diferença nos resultados, ou melhor, porque aparentemente o Grupo Controle parece "mais equilibrado" emocionalmente. O que se pode supor é que as questões relacionadas à imagem corporal, à aparência física e por sua vez ligadas à sexualidade, estão associadas ao processo simbólico de conquistar e ser conquistado (95). O corpo do paciente com ampliação vesical é marcado por cicatrizes das várias operações urológicas e também das fístulas que foram necessárias para o tratamento dialítico 
além do óbvio problema físico. Por essa razão fica difícil investir nesse corpo libidinalmente e usá-lo como na sedução do outro.

A partir dessa investigação nasce uma possibilidade de trabalho a ser desenvolvido pelo psicólogo, com esses pacientes. Ele se focaria em fortalecer a auto-estima dos pacientes e conseqüentemente a auto-aceitação. Isso possibilitaria resgatar e/ou suscitar no paciente potencialidades que permitiriam um melhor ajuste nessa área.

Outra questão é referente às dificuldades ligadas ao autocaterismo vesical. Ainda criança a sondagem mobiliza a descoberta e o questionamento da sexualidade prematuramente. As manipulações intensificam os questionamentos e fantasias do paciente com relação à sua sexualidade $(94,95)$. Há também a questão de que o cateterismo produz na família do paciente fantasias acerca desse procedimento. Segundo Araujo (96) esse procedimento produz fantasias de que o hímen pode ser rompido pela sondagem e mesmo a ereção no momento da manipulação pode provocar desconforto para a família e o paciente. Tendo em vista que esses pacientes se desenvolvem dentro de perspectivas, crenças e valores muito particulares, ele pode internalizar essas fantasias ou a ansiedade da família com essas questões. Se a visão da família com relação à sondagem estiver cercada de estigma, o paciente terá problemas com sua sexualidade (94).

O Grupo Controle teve um comportamento bastante aparentemente "equilibrado" se pensarmos

O resultado das correlações no Grupo Controle mostrou que as facetas contribuíram de igual maneira para o resultado dos domínios. Pode-se pensar em um grupo mais "equilibrado", emocionalmente ajustado, mas não é isso que acontece. 
Quando olhamos para os resultados individuais dos pacientes vemos que há flutuações de maior e menor escore em várias facetas. O que pode demonstrar que para alguns, determinados aspectos são mais importantes do que para outros. O que podemos dizer objetivamente é que não houve aspectos que contribuíssem mais no resultado final do grupo.

Com o Grupo Caso o comportamento foi diferente porque esses pacientes têm que se haver com outros tipos de questões que estão ligadas à sua patologia crônica de nascimento. Eles trazem questões de limitações e impossibilidades há muito mais tempo que os pacientes do outro grupo e isso repercute na maneira como ele lida objetivamente com sua vida. Por essa razão alguns aspectos da Qualidade de Vida para esses pacientes têm maior relevância do que para os pacientes do outro grupo.

Nossos dados apontam para uma diferença entre os dois grupos em relação ao Domínio Social e abrem uma proposta de trabalho psicológico nestes pacientes para melhor adaptá-los a este potencial déficit tentando amenizá-los e assim, equalizar ainda mais os resultados junto aos demais transplantados. O enfoque dessa proposta de trabalho é tanto social quanto clínico.

Se esta intervenção irá ou não obter este resultado, permanece por ser esclarecido num estufo futuro levando em conta esta preparação. 


\section{6 - CONCLUSÕES}

1. A Qualidade de Vida do paciente transplantado renal submetido à ampliação vesical é semelhante em quase todos os domínios do WHOQOL-Abreviado.

2. O Domínio Relações Sociais que avalia percepção do paciente sobre os relacionamentos sociais e os papéis sociais adotados na vida, é signficativamente menor para o Grupo Caso.

3. Esse resultado parece estar diretamente ligado à particularidade da patologia urológica do Grupo Caso. 


\section{7 - ANEXOS}

\section{Anexo A - TERMO DE CONSENTIMENTO LIVRE E ESCLARECIDO}

(Instruções para preenchimento no verso)

\section{I - DADOS DE IDENTIFICAÇÃO DO SUJEITO DA PESQUISA OU RESPONSÁVEL LEGAL}

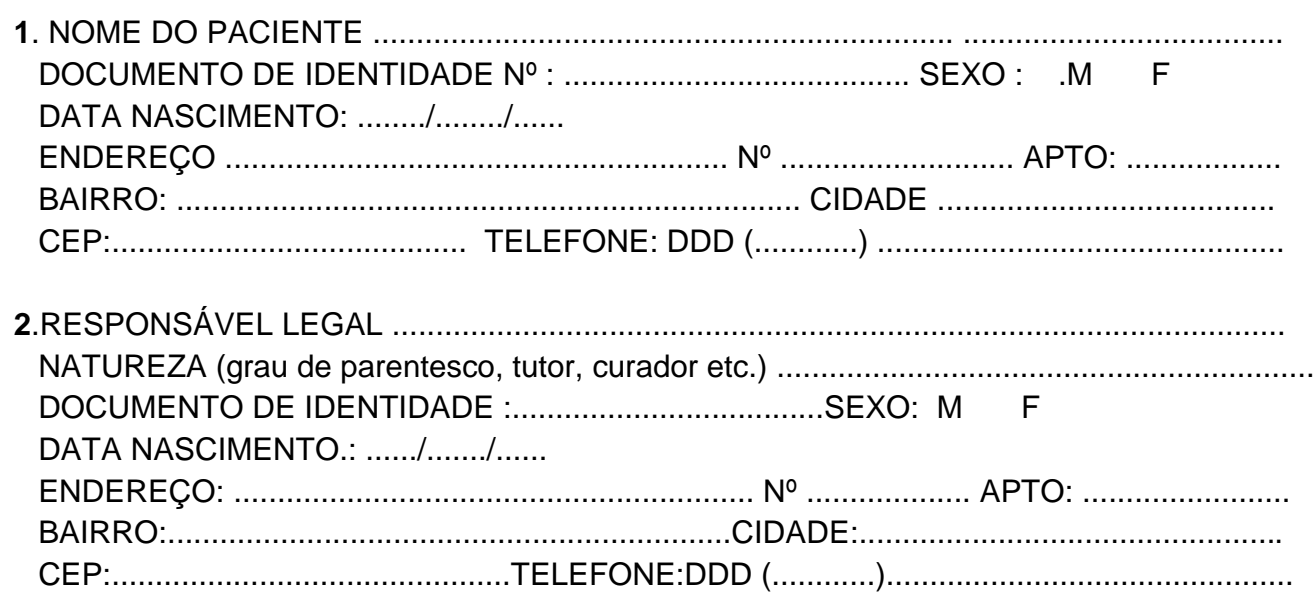

\section{II - DADOS SOBRE A PESQUISA CIENTÍFICA}

1. TÍTULO DO PROTOCOLO DE Qualidade de vida do paciente transplantado renal submetido à ampliação vesical

PESQUISADOR Rita de Cássia do Amaral

CARGO/FUNÇÃO: Pós-Graduanda da Clínica de Nefrologia - FMUSP

INSCRIÇÃO CONSELHO REGIONAL No 06/69.325

UNIDADE DO HCFMUSP: Unidade de Transplante Renal / Clínica de Nefrologia

3. AVALIAÇÃO DO RISCO DA PESQUISA:

$\begin{array}{lll}\text { SEM RISCO } & \mathbf{X} & \text { RISCO MÍNIMO } \\ \text { RISCO BAIXO } & \text { RISCO MAIOR } & \end{array}$

(probabilidade de que o indivíduo sofra algum dano como conseqüência imediata ou tardia do estudo) 


\section{III - REGISTRO DAS EXPLICAÇÕES DO PESQUISADOR AO PACIENTE OU SEU REPRESENTANTE LEGAL SOBRE A PESQUISA CONSIGNANDO:}

1. justificativa e os objetivos da pesquisa.2. procedimentos que serão utilizados e propósitos, incluindo a identificação dos procedimentos que são experimentais.3. desconfortos e riscos esperados. 4. benefícios que poderão ser obtidos.5. procedimentos alternativos que possam ser vantajosos para o indivíduo

Estou sendo convidado a participar de uma pesquisa que está sendo feita aqui no Instituto Central do HCFMUSP para avaliar a qualidade de vida do paciente renal crônico transplantado com ampliação vesical.. Esta pesquisa tem por título "Avaliação da qualidade de vida do paciente renal crônico transplantado submetido à ampliação vesical". Se eu concordar em participar da pesquisa, me será pedido que responda um questionário de qualidade de vida e darei uma entrevista que será gravada em áudio. Isto deverá durar entre 40 e 60 minutos. Não há nenhum risco em minha participação nessa pesquisa.

Caso eu concorde em participar, todas as informações que possam ajudar na minha identificação serão omitidas do trabalho final, para preservar minha privacidade e garantir o sigilo das informações. Por outro lado, as informações que eu puder dar, juntamente com as de outras pessoas, podem auxiliar em uma maior compreensão da qualidade de vida do paciente renal crônico transplantado submetido à ampliação vesical. Tenho ciência que não receberei qualquer benefício direto como resultado de minha participação. Se eu preferir não participar dessa pesquisa, isso não afetará o tratamento que recebo no hospital. Compreendo que os resultados dessa pesquisa serão dados a mim, caso eu os solicite, e que a Psic. Rita de Cássia do Amaral é a pessoa a quem devo contatar, em caso de dúvidas sobre o estudo ou sobre os meus direitos como participante. Estou ciente que a pesquisa tem a garantia de ser livre. Fui informado que, mesmo após seu início, posso recusar-me a responder a qualquer pergunta específica ou a decidir acerca de concluir ou não o preenchimento do questionário, em qualquer parte do mesmo.

\section{IV - ESCLARECIMENTOS DADOS PELO PESQUISADOR SOBRE GARANTIAS DO SUJEITO}

\section{DA PESQUISA CONSIGNANDO:}

1. acesso, a qualquer tempo, às informações sobre procedimentos, riscos e benefícios relacionados à pesquisa, inclusive para dirimir eventuais dúvidas.

2. liberdade de retirar seu consentimento a qualquer momento e de deixar de participar do estudo, sem que isto traga prejuízo à continuidade da assistência.

3. salvaguarda da confidencialidade, sigilo e privacidade.

4. disponibilidade de assistência no HCFMUSP, por eventuais danos à saúde, decorrentes da pesquisa.

5. viabilidade de indenização por eventuais danos à saúde decorrentes da pesquisa.

\section{INFORMAÇÕES DE NOMES, ENDEREÇOS E TELEFONES DOS RESPONSÁVEIS PELO ACOMPANHAMENTO DA PESQUISA, PARA CONTATO EM CASO DE INTERCORRÊNCIAS CLÍNICAS E REAÇÕES ADVERSAS.}

Secretaria da UTR do ICHC FMUSP- telefone: 30698084

\section{OBSERVAÇÕES COMPLEMENTARES:}

VII - CONSENTIMENTO PÓS-ESCLARECIDO

Declaro que, após convenientemente esclarecido pelo pesquisador e ter entendido o que me foi explicado, consinto em participar do presente Protocolo de Pesquisa

São Paulo, de de 200 . 
Anexo B - WHOQOL-ABREVIADO 


\section{Anexo C - FICHA DE CARACTERIZAÇÃO DO SUJEITO}

Identificação:

RGHC:

Data da Aplicação:

Protocolo:

Sexo: ( 1 ) Masculino

(2) Feminino

Idade:

Faixa Etária: ( 1 ) de 18 a 20 anos

( 2 ) de 21 a 34 anos

( 3 ) de 35 a 49 anos

( 4 ) de 50 a 64 anos

( 5 ) maior de 65 anos

Estado civil: ( 1 ) solteiro ( 4 ) divorciado

( 2 ) casado

( 5 ) viúvo

( 3 ) companheiro/amasiado

( 6 ) outros

Tem Parceiro: ( 1 ) sim

( 2 ) não

Escolaridade: ( 1 ) analfabeto

( 6 ) médio incompleto

( 2 ) alfabetizado

( 7 ) superior completo

( 3 ) fundamental completo

( 8 ) superior incompleto

( 4 ) fundamental incompleto

( 5 ) médio completo

( 9 ) pós-graduação

Ocupação: ( 1 ) do lar

( 2 ) estudante

( 3 ) em atividade normal (exercendo atividade profissional rotineiramente)

( 4 ) em licença médica; afastado do trabalho

( 5 ) em atividade no mercado informal

( 6 ) aposentado

( 7 ) desempregado

Religião: ( 1 ) católica

( 4 ) testemunha de Jeová

( 2 ) protestante

( 5 ) outras

( 3 ) espírita

Praticante: ( 1 ) sim

( 3 ) esporadicamente

( 2 ) não

( 4 ) não se aplica 
Renda pessoal: ( 1 ) até $1 \mathrm{SM} \quad$ Renda Familiar: ( 1 ) até $1 \mathrm{SM}$

$$
\begin{aligned}
& (2)>1 \text { e } \leq 4 \mathrm{SM} \\
& (3)>5 \text { e } \leq 7 \mathrm{SM} \\
& (4)>8 \text { e } \leq 10 \mathrm{SM} \\
& (5)>11 \mathrm{SM} \\
& \text { (6) sem renda }
\end{aligned}
$$

Tempo de Tx:

Tempo em Faixa: ( 1 ) menos de 1 ano

(2) de 1 a 3 anos

( 3 ) de 4 a 7 anos

( 4 ) de 8 a 12 anos

( 5 ) acima de 13 anos

Tipo de Doador: ( 1 ) Vivo

( 2 ) Falecido

Número do Tx:

Creatinina:

Faixa de Creatinina: ( 1 ) menor ou igual a $1,5 \mathrm{mg} / \mathrm{dl}$

( 2 ) de 1,6 a $2,5 \mathrm{mg} / \mathrm{dl}$

( 3 ) maior ou igual a $2,6 \mathrm{mg} / \mathrm{dl}$

$\begin{array}{llll}\text { Imunossupressão: } & \text { Prednisona } & \text { ( } 1 \text { ) } \operatorname{sim} & \text { ( } 2 \text { ) não } \\ & \text { Azatioprina } & \text { ( } 1) \operatorname{sim} & \text { ( } 2 \text { ) não } \\ & \text { Rapamicina } & \text { ( } 1) \operatorname{sim} & \text { ( } 2 \text { ) não } \\ & \text { Micofenolato } & \text { ( } 1) \operatorname{sim} & \text { ( } 2) \text { não } \\ & \text { Tacromilus } & \text { ( } 1 \text { ) } \operatorname{sim} & \text { ( } 2) \text { não } \\ \text { Ciclosporina } & \text { ( } 1 \text { ) } \operatorname{sim} & \text { ( } 2 \text { ) não }\end{array}$

Ampliação Vesical: ( 1 ) sim (2) não

Motivo: ( 1 ) Bexiga Neurogênica

( 2 ) Extrofia Vesical

( 3 ) Outros

( 4 ) Não se aplica 
Dificuldades de Locomoção: ( 1 ) sim

( 2 ) não

Se sim: (1 ) usa muletas

( 2 ) usa cadeira de rodas

( 3 ) usa aparelho ortopédico

( 4 ) coxo

( 5 ) não se aplica

Faz Cateterismo ( 1 ) sim ( 2 ) não ( 3 ) não se aplica

Tem Escapes ( 1 ) $\operatorname{sim}$ ( 2 ) não ( 3 ) não se aplica

Usa Foro ( 1 ) $\operatorname{sim}$ ( 2 ) não ( 3 ) não se aplica 


\title{
Anexo D - SÍNTESE ESTATÍSTICA PARA CÁLCULO DO WHOQOL- ABREVIADO
}

\author{
STEPS FOR CHECKING AND CLEANING DATA AND COMPUTING \\ DOMAIN SCORES FOR THE WHOQOL-BREF \\ (prepared by Alison Harper and Mick Power on behalf of the WHOQOL Group)
}

\begin{tabular}{|c|c|}
\hline Steps & $\begin{array}{l}\text { SPSS syntax for carrying out data checking,cleaning and } \\
\text { computing total scores }\end{array}$ \\
\hline $\begin{array}{l}\text { Check all } \\
26 \text { items } \\
\text { from } \\
\text { assessment } \\
\text { have a } \\
\text { range of } 1-5\end{array}$ & $\begin{array}{l}\text { RECODE Q1 Q2 Q3 Q4 Q5 Q6 Q7 Q8 Q9 Q10 Q11 Q12 Q13 Q14 } \\
\text { Q15 Q16 Q17 Q18 Q19 } 120 \text { Q21 Q22 Q23 Q24 Q25 Q26 } \\
(1=1)(2=2)(3=3)(4=4) \text { (5=5) (ELSE=SYMSIS). } \\
\text { (This recodes all data outside the range 1-5 to system missing) }\end{array}$ \\
\hline $\begin{array}{l}\text { Reverse } 3 \\
\text { negatively } \\
\text { phrased } \\
\text { items }\end{array}$ & $\begin{array}{l}\text { RECODE Q3 Q4 Q26 }(1=5)(2=4)(3=3)(4=2)(5=1) \\
\text { (This transforms negatively framed questions to positively framed } \\
\text { questions) }\end{array}$ \\
\hline $\begin{array}{l}\text { Compute } \\
\text { domain } \\
\text { scores }\end{array}$ & $\begin{array}{l}\text { COMPUTE PHYS= MEAN.6(Q3,Q4,Q10,Q15,Q16,Q17,Q18)*4. } \\
\text { COMPUTE PSYCH= MEAN.5(Q5,Q6,Q7,Q11,Q19,Q26)*4. } \\
\text { COMPUTE SOCIAL=MEAN.2(Q20,Q21,Q22)*4. } \\
\text { COMPUTE ENVIR=MEAN.6(Q8,Q9,Q12,Q13,Q14,Q23,Q24,Q25)*4. } \\
\text { (These equations calculate the domain scores. All scores are multiplied by } \\
4 \text { so as to be directly comparable with scores derived from the WHOQOL- } \\
\text { 100. The ".6" in "MEAN.6" specifies that } 6 \text { items must be endorsed for the } \\
\text { domain score to be calculated.) }\end{array}$ \\
\hline $\begin{array}{l}\text { Transform } \\
\text { scores to } \\
0-100 \text { scale }\end{array}$ & $\begin{array}{l}\text { COMPUTE PHYS }=(\text { PHYS-4 })^{*}(100 / 16) \\
\text { COMPUTE PSYCH }=(\text { PSYCH-4 })^{*}(100 / 16) \\
\text { COMPUTE SOCIAL }=(\text { SOCIAL- } 4) *(100 / 16) \\
\text { COMPUTE ENVIR }=(\text { ENVIR-4 })^{*}(100 / 16)\end{array}$ \\
\hline $\begin{array}{l}\text { Delete cases } \\
\text { with }>20 \% \\
\text { missing } \\
\text { data }\end{array}$ & $\begin{array}{l}\text { COUNT TOTAL=Q1 TO Q26 (1 THRU 5) } \\
\text { (This command creates a new column "total". "Total" contains a count of } \\
\text { the WHOQOL-BREF items with values 1-5 that have been endorsed by } \\
\text { each subject. The "Q1 TO Q26" means that consecutive columns from } \\
\text { "Q1", the first item, to "Q26", the last item, are included in the count. It } \\
\text { therefore assumes that data is entered in the order given in the assessment.) } \\
\text { SELECT IF (TOTAL>21). EXECUTE } \\
\text { (This second command selects only those cases where "total", the "total } \\
\text { number" of items completed, is greater than or equal to } 80 \% \text {. It deletes the } \\
\text { remaining cases from the dataset.) }\end{array}$ \\
\hline
\end{tabular}




\section{8 - REFERÊNCIAS BIBLIOGRÁFICAS}

1. Bowling A, Brazier J. Quality of life in social science an medicine. Soc Sc E Med. 1995;41(10):1337-8.

2. Pilon AF. Qualidade de vida e formas de relacionamento homem/mundo Rev bras saúde esc. 1992 jul-dez;2(3/4):117-25.

3. Lima SMRR, Tedesco JJA. Aspectos emocionais da falência ovariana prematura. Femina. 2008 mar;36(3):165-9.

4. Kran F, FERREIRA FPM. Qualidade de vida na cidade de Palmas - TO: uma análise através de indicadores habitacionais e ambientais urbanos. Ambient soc. 2006 jun/dez;9(2):123-41.

5. Ometto AMH, Furtuoso MCO, Silva MV. Economia brasileira na década de oitenta e seus reflexos nas condições de vida da população. Rev Saúde Pública 1995 Ouct;29(5):403-14.

6. Trompenaars FJ, Masthoff ED, Van Heck GL, Hodiamont PP, Vries JD. Content validity, construct validity, and reliability of the WHOQOL-Bref in a population of Dutch adult psychiatric outpatients Quality of Life Research. 2005 February;14(1):151-60.

7. Velasco M, Lezama E, Contreras F, Hernández R, Hernández M, Alcocer L, et al. Semipersonalized psychological evaluation of quality of life of hypertensive patients in a trial with two calcium antagonists: a multicenter Latinamerican study (Lastlhy). Arch venez farmacol ter. 2000;19(2):129-31.

8. Pinheiro ACFB, Monteiro ALFBP. Ciencias do ambiente; ecologia, poluiçao e impacto ambiental. . São Paulo: Makron; 1992.

9. Wimmer GF, Figueiredo GO. Ação coletiva para qualidade de vida: autonomia, transdisciplinaridade e intersetorialidade. Ciênc saúde coletiva. 2006 Jan/Mar;11(1):145-54.

10. Hunt SM, McKenna SP. Validating the SF-36. Bmj. 1992 Sep

12;305(6854):645; author reply 6. 
11. Salgado PCB, Souza EAP. Qualidade de vida em epilepsia e percepção de controle de crises. Arq Neuropsiquiatr. 2001 set;59(3A):537-40.

12. Hopkins A. Measures of the quality of life: and the uses to which such measures may be put. London: Royal College of Physicians of London; 1992.

13. Fleck MPA, Louzada S, Xavier M, Chachamovich E, Vieira G, Santos L. A aplicação da versão em português do instrumento de avaliação de qualidade de vida da Organização Mundial da saúde (WHOQOL-100). Rev Saúde Pública. 1999;33(2):198-205.

14. Bullinger M, Anderson R, Cella D, Aaronson N. Developing and evaluating cross-cultural instruments from minimum requeriments to optimal models. Quality Life Res. 1993 Dec.;2(6):451-9.

15. Barros N. Dor e qualidade de vida em pacientes com câncer. Revista Dor Pesquisa Clínica e Terapêutica. 2000;2(1):24-9.

16. Marques LF. Qualidade de vida, uma aproximação conceitual. PSICO. 1996;27(2):49-62.

17. Barros N. Qualidade de vida - conceitos e métodos de avaliação. In Andrade Filho, A. C. de C. Dor: Diagnóstico e tratamento. São Paulo: Roca; 2001.

18. Romano BW. Qualidade de vida: teoria e prática. Rev SOCESP. 1993 Nov/Dez;3(6 (SUPL a)):6-9.

19. The WHOQOL Group. The World Health Organization Quality of Life Assessment (WHOQOL): position paper from The World Health Organization. Sco Sci Med. 1995;41(10):1403-9.

20. Fleck MPA, Louzada S, Xavier M, Chachamovich E, Vieira G, Santos L, et al. A aplicação da versão em portugês do instrumento abreviado de avaliação de qualidade de vida "WHOQOL-Bref". Rev Saúde Pública. 2000;34(2):178-83.

21. The WHOQOL Group. Development of the World Health Organization WHOQOL-Bref: quality of life assesment. Psychol Med. 1998 May;28(3):551-8. 
22. The WHOQOL Group. The World Health Organization quality of life assessment (WHOQOL): Development and general psychometric properties. Soc Sci Med. 1998 June;46(12):1569-85.

23. Hwang JH, Chang HJ, Shim YH, Park WH, Park W, Huh SJ, et al. Effects of Supervised Exercise Therapy in Patients Receiving Radiotherapy for Breast Cancer. Yonsei Med J. 2008;49(3):443-50.

24. Baptista MN, Juliana Furlan Vargas JF, Baptista ASD. Depressão e qualidade de vida em uma amostra brasileira de obesos mórbidos. Aval psicol. 2008 Ago;7(2):235-47.

25. Costa CC, Bastiani M, Geyer JG, Calvetti PÜ, Muller MC, Moraes MLA. Qualidade de vida e bem-estar espiritual em universitários de Psicologia. Psicol estud. 2008 abr-jun;13 (2):249-55.

26. Carneiro RS, Falcone E, Clark C, Del Prette Z, Del Prette A. Qualidade de vida, apoio social e depressão em idosos: relação com habilidades sociais Psicol Reflex Crit. 2007;20(2):229-37.

27. Bonicatto SC, Dew MA, Zaratiegui R, Lorenzo L, Pecina P. Adult outpatients with depression: worse quality of life than in other chronic medical diseases in Argentina Soc Sci Med. 2001;52(6):911-9.

28. Fleck MPA, Lima AFBS, Louzada S, Schestasky G, Henriques A, Borges VR, et al. Associação entre sintomas depressivos e funcionamento social em cuidados primários à saúde. Rev Saúde Pública. 2002;36(4):431-8.

29. Nicodemo D, Pereira MD, Ferreira LM. Cirurgia ortognática: abordagem psicossocial em pacientes Classe III de Angle submetidos à correção cirúrgica da deformidade dentofacial. Rev Dent Press Ortodon Ortop Facial. 2007 Sept/Ouct;12(5):46-54.

30. Durães MIC. Influência da fonte de célula (progenitora periférica ou medula óssea) na qualidade de vida de pacientes onco-hematológicos submetidos ao transplante alogênico de medula óssea Rev bras hematol hemoter 2002 Mar;24(1):63-4.

31. Michelone APC, Santos VLCG. Qualidade de vida de adultos com câncer colorretal com e sem estoma. Rev Latino-am Enfer. 2004 Nov/Dez;12(6):875-83. 
32. Niu SF, Li IC. Quality of life of patients having renal replacement therapy. J Adv Nurs. 2005 Jul;51(1):15-21.

33. Nunes MF, Freire MCM. Qualidade de vida de cirurgiões-dentistas que atuam em serviço público. Rev Saúde Pública. 2006;40(6):1019-26.

34. Phungrassami T, Katikarn R, Watanaarepornchai S, Sangtawan D. Quality of Life Assessment in Radiotherapy Patients by WHOQOL-BREF-THAI: A Feasibility Study. J Med Assoc Thai. 2004;87(12).

35. Tze Pin Ng, Lionel Chee Chong Lim, Jin A, Shinfuku N. Ethnic differences in quality of life in adolescents among Chinese, Malay and Indians in Singapore Quality of Life Research. 2005 September;14(7):1755-68.

36. Yang SC, Kuo PW, Wang JD, Lin MI, Su S. Development and psychometric properties of the dialysis module of the WHOQOL-BREF Taiwan version. J Formos Med Assoc. 2006 Apr;105(4):299-309.

37. Stengler-Wenzke K, Kroll M, Mastschinger H, Angermeyer MC. Subjective quality of life of patients with obsessive-compulsive disorder. Social psychiatry and psychiatric epidemiology. 2006;41(8):662-8.

38. Brockmann M. Towards a Model of Quality of Life for Older Ethnic Minority Migrants in Germany, Austria and the UK European Societies. 2002 September;4(3):285-306.

39. De Girolamo G, Rucci P, Scocco P, Becchi A, Coppa F, D'Addario A, et al. Quality of life assessment: validation of the Italian version of the WHOQOL-Brief. Epidemiol Psichiatr Soc 2000 Jan-Mar;9(1):45-55.

40. Akvardar Y, Akdede BB, Ozerdem A, Eser E, Topkaya S, Alptekin K. Assessment of quality of life with the WHOQOL-BREF in a group of Turkish psychiatric patients compared with diabetic and healthy subjects. Psychiatry \& Clinical Neurosciences. 2006 December;60(6):693-9.

41. Ekblad S, Abazari A. Migration Stress-Related Challenges Associated with Perceived Quality of Life: A Qualitative Analysis of Iranian Refugees and Swedish Patients Transcultural Psychiatry. 1999;36(3):329-45.

42. Molzahn AE, Pagé G. Field Testing the WHOQOL-100 in Canada Canadian Journal of Nursing Research. 2006 September;38(3):106-23. 
43. Kong IL, Molassiotis A. Quality of life, coping and concerns in Chinese patients after renal transplantation. Int J Nurs Stud. 1999 Aug;36(4):313-22.

44. Li L, Young D, Xiao S, Zhou X, Zhou L. Psychometric properties of the WHO Quality of Life questionnaire (WHOQOL-100) in patients with chronic diseases and their caregivers in China. Bull World Health Organ. 2004 Jul;82(7):493502.

45. Saxena S, Chandiramani K, Bhargava R. WHOQOL-Hindi: a questionnaire for assessing quality of life in health care settings in India. World Health Organization Quality of Life. Natl Med J India. 1998 Jul-Aug;11(4):160-5.

46. Wegener S, Redoblado-Hodge MA, Lucas S, Fitzgerald D, Harris A, Brennan J. Relative contributions of psychiatric symptoms and neuropsychological functioning to quality of life in first-episode psychosis. Australian and New Zealand Journal of Psychiatry. 2005 Jun;39(6):487-92.

47. Narkiss-Guez T, Amir M, Ya'acov YB. Quality of Life Issues among Older Adults in Israel In: Research QoL, editor. 10th Annual Conference of the International Society for Quality of Life Research (ISOQOL); 2003; 2003. p. 850.

48. Hasanah CI, Naing L, Rahman AR. World Health Organization Quality of Life Assessment: brief version in Bahasa Malaysia. Med J Malaysia. 2003 Mar;58(1):79-88.

49. Golimbet V, Trubnikov V. Evaluation of the dementia carers situation in Russia. International Journal of Geriatric Psychiatry. 2001 Jan;Volume 16 Issue 1, Pages 94 - 99(1):94-9.

50. Tomasz W, Piotr S. A trial of objective comparison of quality of life between chronic renal failure patients treated with hemodialysis and renal transplantation. Ann Transplant. 2003;8(2):47-53.

51. Wesolowski T, Szyber P. [Usage of the WHOQOL-100 as a trial of objective estimation of quality of life in end-stage renal disease patients treated with renal transplantation]. Pol Merkur Lekarski. 2004 Sep;17(99):260-6.

52. Lazzaretti CT, Cavalho JGR, Mulinari RA, Rasia JM. Kidney transplantation improves the multidimensional qualkity of life. Transplant Proc. 2004;36:872-73. 
53. Greenwell TJ, Venn SN, Mundy AR. Augumentation cystoplasty. BJU International. 2001;88:511-25.

54. Lapides J, Diokno AC, Silber SJ, Lowe BS. Clean intermittent self catheterization in the treatment of urinary tract disease. J Urol. 1972;107:458-61.

55. Robertson AS, Davies JB, Webb RJ, Neal DE. Bladder augmentation and replacement: urodynamicand clinical review of 25 patients. BJU International. 1991;68:590-7.

56. Figueiredo AA, Lucon AM, Srougi M. Bladder augmentation for the treatment of chronic tuberculous cystitis. Clinical and urodynamic evaluation of 25 patients after long term follow-up. Neurourol Urodyn. 2006;25(5):433-40.

57. Bruschini H. Capítulo 47. In Barata, H. Carvalhal, G. (org). Urologia: Princípios e práticas. . São Paulo: Segmento; 1999.

58. Zerati Filho M, Barroso Júnior U. Disfunção miccional na infância. In: Guia prático de urologia. São Paulo: Segmento; 2003.

59. Nahas WC, Fugita OEH, Mazzucchi E, Antonopoulos I, David-Neto E, Ianhez LE, et al. Transplante renal em bexiga refuncionalizada. $26^{\circ}$ Congresso de Urologia; 1997; Blumenau-SC - Brasil; 1997.

60. Nahas WC, Mazzucchi E, Antonopoulos I, David-Neto E, Ianhez LE, Sabbaga E, et al. Kidney transplantation in patients with bladder augmentation: surgical outcome and urodynamic follow-up. Transplant Proc. 1997 Feb-Mar;29(12):157-8.

61. Nahas WC, Mazzucchi E, Antonopoulos I, Denes FT, David-Neto E, Ianhez LE, et al. End-stage renal disease and bladder dysfunction: algorithm for renal transplantation. Transplant Proc. 2001 Sep;33(6):2984-5.

62. Nahas WC, Mazzucchi E, Antonopoulos I, Piovesan A, Araujo LMP, DavidNeto E, et al. Ureterocystoplasty and kidney transplant - the best technique for bladder enlargement in patients with ESRD and bladder dysfunction. American Transplant Congress; 200330 de maio a 04 de junho; Washington-Estados Unidos; 2003.

63. Romano BW, Maio SAB, Bocchi E, Moreira LF, Stolf N, Barreto ACP, et al. Qualidade de vida após cardiomiopatia. Rev SOCESP. 1991;1(2):7-12. 
64. Fleck MPA, Leal OF, Louzada S, Xavier M, Chachamovich E, Vieira G, et al. Desenvolvimento da versão em português do instrumento de avaliação de qualidade de vida da OMS (WHOQOL-100) Rev Bras Psiquiatr vol21 n1 São Paulo Jan/Mar 1999. 1999 Jan/Mar;21(1):19-28.

65. Kelly WD, Merkel FK, Markland C. Ileal urinary diversion in conjuction with renal homotransplantation. Lancet. 1966;1:222-6.

66. Marshal FF, Smolev JK, Spees EK, Jeffs RD, Burdick JF. The urological evaluation and management of patients with congenital lower urinary tract anomalies prior to renal transplantation. J Urol. 1982;127:1078-81.

67. Stephenson TP, Salaman JR, Stone AR, Murray KH, Griffin P. Urinary tract reconstruction before renal transplantation. Transplant Proc. 1984;16:1340-1.

68. Zubieta R, De Badiola F, Escala JM, et al. Clinical and urodynamic evaluation after ureterocystoplaty with different amounts of tissue. J Urol. 1999;162:1129-32.

69. Ali-El-Dein B, Abol-Enein H, El-Husseini A, Osman Y, Shehab El-Din AB, Ghoneim MA. Renal transplantation in children with abnormal lower urinary tract. Transplant Proc. 2004;36:2968-73.

70. Capazzi A, Zanon GF, Zacchello G, Rigamonti W. Kidney transplantation in children with reconstructed bladder. Transplantation. 2004;77:1113-6.

71. Santos CT, Sebastiani RW. Acompanhamento psicológico à pessoa portadora de doença crônica. In: Angerami-Camon, V. A. et. al. E a psicologia entrou no hospital. São Paulo: Pioneira Thonson Learning; 1996.

72. Silva I, Ribeiro JLP, Cardoso H, Ramos H, Carvalhosa SF, Dias S, et al. Efeitos do apoio social na qualidade de vida, controle metabolico e desenvolvimento de complicações crônicas em indivíduos com diabetes. Psicologia, Saúde e Doenças. 2003;4(1):21-32.

73. Alapont Alacreu JM, Pacheco Bru JJ, Pontones Moreno JL, Alonso Gorrea M, Sanchez Plumed J, Jimenez Cruz FJ. [Renal transplantation in patients with enterocystoplasty]. Actas Urol Esp. 2003 Apr;27(4):281-5. 
74. Arguelles Salido E, Barrero Candau R, Torrubia Romero FJ, Cruz Navarro N, Leal Arenas J, Montanes Medina P. [Bladder augmentation and urinary diversion in kidney transplant candidates]. Arch Esp Urol. 2004 Sep;57(7):699-705.

75. Barnett MG, Bruskewitz RC, Belzer FO, Sollinger HW, Uehling DT. Ileocecocystoplasty bladder augmentation and renal transplantation. J Urol. 1987 Oct;138(4):855-8.

76. Basiri A, Hosseini Moghaddam S, Khoddam R. Augmentation cystoplasty before and after renal transplantation: long-term results. Transplant Proc. 2002 Sep;34(6):2106-8.

77. Basiri A, Simforoosh N, Khoddam R, Hosseini Moghaddam SM, Shayani Nasab H. A comparison of augmentation cystoplasty before and after renal transplantation with the control group. Urol J. 2004 Winter;1(1):45-8.

78. Mendizabal S, Estornell F, Zamora I, Sabater A, Ibarra FG, Simon J. Renal transplantation in children with severe bladder dysfunction. J Urol. 2005 Jan;173(1):226-9.

79. Rigamonti W, Capizzi A, Zacchello G, Capizzi V, Zanon GF, Montini G, et al. Kidney transplantation into bladder augmentation or urinary diversion: long-term results. Transplantation. 2005 Nov 27;80(10):1435-40.

80. Taghizadeh AK, Desai D, Ledermann SE, Shroff R, Marks SD, Koffman G, et al. Renal transplantation or bladder augmentation first? A comparison of complications and outcomes in children. BJU Int. 2007 Dec;100(6):1365-70.

81. Thomalla JV, Lingeman JE, Leapman SB, Filo RS. The manifestation and management of late urological complications in renal transplant recipients: use of the urological armamentarium. J Urol. 1985 Nov;134(5):944-8.

82. Thomalla JV, Mitchell ME, Leapman SB, Filo RS. Renal transplantation into the reconstructed bladder. J Urol. 1989 Feb;141(2):265-8.

83. Cicconelli RM. Tradução para o português e validação do questionário genérico de avaliação de qualidade de vida "Medical Outcomes Study 36-Item Short form Health Survey (SF-36)". São Paulo: UNIFESP; 1997.

84. Ware JE, Sherbourne CD. The MOS 36-item short form health survey (SF36): conceptual framework and item selection. Med Care. 1992;30(6):473-83. 
85. Rebollo P, Gonzalez MP, Bobes J, Saiz P, Ortega F. Interpretation of healthrelated quality of life of patients on replacement therapy in end-stage renal disease. Nefrologia. 2000;20(5):431-9.

86. Sureshkumar KK, Mubim T, Mikael N, Kashif MA, Nghiem DD, Marcus RJ. Assessment of quality of life after simultaneous pancreas-kidney transplantation. Am J Kidney Dis. 2002;39(6):1300-06.

87. Wasserman MDA. Princípios de tratamento psiquiátrico de crianças e adolescentes com doenças físicas. In: Garfinkel, B.et al. Transtornos psiquiátricos na infância e adolescência. Porto alegre; 1992.

88. Vieira MA, Lima RAG. Crianças e adolescentes com doença crônica: convivendo com mudanças. Rev Latino-am Enfer. 2002;10(4):552-60.

89. Castro EK, Piccinini CA. Implicações da doença orgânica crônica na infância para as relações familiares: algumas questões teóricas. Psicologia: Reflexão e Crítica. 2002;15(3):625-35.

90. Cohen S. Psychosocial models of the role of social support in the etiology of physical disease. Health Psychology. 1988;7:269-97.

91. Emmons RA, Colby PM. Emotional conflict and well-being: relation to perceived availability, daily utilization, and observer reports of social support. Journal of Personality and Social Psychology. 1995;68(5):947-59.

92. Pierce GR, Sarason BR, Sarason IG. General and specific support expectations and stress as predictors of perceived supportiveness: an experimental study. Journal of Personality and Social Psychology. 1992;63(2):297-307.

93. Vilhjalmsson R. Effects of social support on self-assessed health in adolescence. Journal of Youth and Adolescence. 1994;23(4):437-52.

94. Soares AHR, Moreira MCN, Monteiro LMC. Jovens portadores de deficiência: sexualidade e estigma. Ciênc saúde coletiva. 2008;13(1):185-94.

95. Soares AHR, Moreira MCN, Monteiro LMC, Pohl HG. A qualidade de vida de jovens portadores de espinha bífida do Childre's National Medical Center Washington DC. Ciênc saúde coletiva. 2006;11(3):817-26. 
96. Araujo GF. Repercusões do cateterismo intermitente na vida dos pais de crianças portadoras de mielomeningocele. Rio de Janeiro: Fundação Oswaldo Cruz; 2000 . 


\section{9 - BIBLIOGRAFIAS CONSULTADAS}

Dancey CP, Reydi J. Estatística sem matemática para psicologia: usando spss para windows. Porto Alegre: Artmed; 2006.

Guéguen N. Manual de estatística para psicólogos. Lisboa/Portugal: Climepsi; 1997.

Laplanche J, Pontalis JB. Vocabulário de psicanálise. São Paulo: Martins Fontes; 2001 


\section{WHOQOL - ABREVIADO \\ Versão em Português}

\section{PROGRAMA DE SAÚDE MENTAL ORGANIZAÇÃO MUNDIAL DA SAÚDE GENEBRA}

Coordenação do GRUPO WHOQOL no Brasil

Dr. Marcelo Pio de Almeida Fleck

Professor Adjunto

Departamento de Psiquiatria e Medicina Legal

Universidade Federal do Rio Grande do Sul

Porto Alegre - RS - Brasil 


\section{Instruções}

Este questionário é sobre como você se sente a respeito de sua qualidade de vida, saúde e outras áreas de sua vida. Por favor, responda a todas as questões . Se você não tem certeza sobre que resposta dar em uma questão, por favor, escolha entre as alternativas a que lhe parece mais apropriada. Esta, muitas vezes, poderá ser sua primeira escolha.

Por favor, tenha em mente seus valores, aspirações, prazeres e preocupações. Nós estamos perguntando o que você acha de sua vida, tomando como referência as duas últimas semanas. Por exemplo, pensando nas últimas duas semanas, uma questão poderia ser:

\begin{tabular}{||l|c|c|c|c|c||}
\hline \hline & nada & $\begin{array}{c}\text { muito } \\
\text { pouco }\end{array}$ & médio & muito & completamente \\
\hline $\begin{array}{l}\text { Você recebe dos outros o apoio de que } \\
\text { necessita? }\end{array}$ & 1 & 2 & 3 & 4 & 5 \\
\hline
\end{tabular}

Você deve circular o número que melhor corresponde ao quanto você recebe dos outros o apoio de que necessita nestas últimas duas semanas. Portanto, você deve circular o número 4 se você recebeu "muito" apoio como abaixo.

\begin{tabular}{||l|c|c|c|c|c||}
\hline & nada & $\begin{array}{c}\text { muito } \\
\text { pouco }\end{array}$ & médio & muito & completamente \\
\hline $\begin{array}{l}\text { Você recebe dos outros o apoio de que } \\
\text { necessita? }\end{array}$ & 1 & 2 & 3 & 4 & 5 \\
\hline
\end{tabular}

Você deve circular o número 1 se você não recebeu "nada" de apoio. 
Por favor, leia cada questão, veja o que você acha e circule no número e lhe parece a melhor resposta.

\begin{tabular}{||l|l|c|c|c|c|c||}
\hline & & $\begin{array}{c}\text { muito } \\
\text { ruim }\end{array}$ & ruim & $\begin{array}{c}\text { nem ruim } \\
\text { nem boa }\end{array}$ & $\begin{array}{c}\text { boa } \\
\text { boa }\end{array}$ \\
\hline 1 & $\begin{array}{l}\text { Como você avaliaria sua qualidade de } \\
\text { vida? }\end{array}$ & 1 & 2 & 3 & 4 & 5 \\
\hline
\end{tabular}

\begin{tabular}{||l|l|l|l|c|c|c||}
\hline \hline & $\begin{array}{l}\text { muito } \\
\text { insatisfeito }\end{array}$ & insatisfeito & $\begin{array}{c}\text { nem satisfeito } \\
\text { nem insatisfeito }\end{array}$ & satisfeito & $\begin{array}{c}\text { muito } \\
\text { satisfeit } \\
0\end{array}$ \\
\hline 2 & $\begin{array}{l}\text { Quão satisfeito(a) você está } \\
\text { com a sua saúde? }\end{array}$ & 1 & 2 & 3 & 4 & 5 \\
\hline
\end{tabular}

As questões seguintes são sobre o quanto você tem sentido algumas coisas nas últimas duas semanas.

\begin{tabular}{||l|l|c|c|c|c|c||}
\hline & & nada & $\begin{array}{c}\text { muito } \\
\text { pouco }\end{array}$ & $\begin{array}{c}\text { mais ou } \\
\text { menos }\end{array}$ & $\begin{array}{l}\text { bastant } \\
\text { e }\end{array}$ & extremamente \\
\hline 3 & $\begin{array}{l}\text { Em que medida você acha que sua dor } \\
\text { (física) impede você de fazer o que você } \\
\text { precisa? }\end{array}$ & 1 & 2 & 3 & 4 & 5 \\
\hline 4 & $\begin{array}{l}\text { O quanto você precisa de algum } \\
\text { tratamento médico para levar sua vida } \\
\text { diária? }\end{array}$ & 1 & 2 & 3 & 4 & 5 \\
\hline 5 & O quanto você aproveita a vida? & 1 & 2 & 3 & 4 & 5 \\
\hline 6 & $\begin{array}{l}\text { Em que medida você acha que a sua vida } \\
\text { tem sentido? }\end{array}$ & 1 & 2 & 3 & 4 & 5 \\
\hline 7 & O quanto você consegue se concentrar? & 1 & 2 & 3 & 4 & 5 \\
\hline 8 & $\begin{array}{l}\text { Quão seguro(a) você se sente em sua vida } \\
\text { diária? }\end{array}$ & 1 & 2 & 3 & 4 & 5 \\
\hline 9 & $\begin{array}{l}\text { Quão saudável é o seu ambiente físico } \\
\text { (clima, barulho, poluição, atrativos)? }\end{array}$ & 1 & 2 & 3 & 4 & 5 \\
\hline \hline
\end{tabular}

As questões seguintes perguntam sobre

quão completamente você tem sentido ou é capaz de fazer certas coisas nestas últimas duas semanas.

\begin{tabular}{||l|l|c|c|c|c|c||}
\hline & & nada & $\begin{array}{l}\text { muito } \\
\text { pouco }\end{array}$ & médio & muito & completamente \\
\hline 10 & Você tem energia suficiente para seu dia-a-dia? & 1 & 2 & 3 & 4 & 5 \\
\hline 11 & Você é capaz de aceitar sua aparência física? & 1 & 2 & 3 & 4 & 5 \\
\hline 12 & $\begin{array}{l}\text { Você tem dinheiro suficiente para satisfazer suas } \\
\text { necessidades? }\end{array}$ & 1 & 2 & 3 & 4 & 5 \\
\hline 13 & $\begin{array}{l}\text { Quão disponíveis para você estão as } \\
\text { informações que precisa no seu dia-a-dia? }\end{array}$ & 1 & 2 & 3 & 4 & 5 \\
\hline 14 & $\begin{array}{l}\text { Em que medida você tem oportunidades de } \\
\text { atividade de lazer? }\end{array}$ & 1 & 2 & 3 & 4 & 5 \\
\hline
\end{tabular}


As questões seguintes perguntam sobre quão bem ou satisfeito você se sentiu a respeito de vários aspectos de sua vida nas últimas duas semanas.

\begin{tabular}{||l|l|c|c|c|c|c||}
\hline \hline & & $\begin{array}{c}\text { muito } \\
\text { ruim }\end{array}$ & ruim & $\begin{array}{c}\text { nem ruim } \\
\text { nem bom }\end{array}$ & $\begin{array}{c}\text { bom } \\
\text { bom }\end{array}$ \\
\hline 15 & Quão bem você é capaz de se locomover? & 1 & 2 & 3 & 4 & 5 \\
\hline
\end{tabular}

\begin{tabular}{|c|c|c|c|c|c|c|}
\hline & & $\begin{array}{c}\text { muito } \\
\text { insatisfeito }\end{array}$ & insatisfeito & $\begin{array}{c}\text { nem satisfeito } \\
\text { nem insatisfeito }\end{array}$ & satisfeito & $\begin{array}{c}\text { muito } \\
\text { satisfeito }\end{array}$ \\
\hline 16 & $\begin{array}{l}\text { Quão satisfeito(a) você está com o seu } \\
\text { sono? }\end{array}$ & 1 & 2 & 3 & 4 & 5 \\
\hline 17 & $\begin{array}{l}\text { Quão satisfeito(a) você está com sua } \\
\text { capacidade de desempenhar as atividades } \\
\text { do seu dia-a-dia? }\end{array}$ & 1 & 2 & 3 & 4 & 5 \\
\hline 18 & $\begin{array}{l}\text { Quão satisfeito(a) você está com sua } \\
\text { capacidade para o trabalho? }\end{array}$ & 1 & 2 & 3 & 4 & 5 \\
\hline 19 & $\begin{array}{l}\text { Quão satisfeito(a) você está consigo } \\
\text { mesmo? }\end{array}$ & 1 & 2 & 3 & 4 & 5 \\
\hline 20 & $\begin{array}{l}\text { Quão satisfeito(a) você está com suas } \\
\text { relações pessoais (amigos, parentes, } \\
\text { conhecidos, colegas)? }\end{array}$ & 1 & 2 & 3 & 4 & 5 \\
\hline 21 & $\begin{array}{l}\text { Quão satisfeito(a) você está com sua vida } \\
\text { sexual? }\end{array}$ & 1 & 2 & 3 & 4 & 5 \\
\hline 22 & $\begin{array}{l}\text { Quão satisfeito(a) você está com o apoio } \\
\text { que você recebe de seus amigos? }\end{array}$ & 1 & 2 & 3 & 4 & 5 \\
\hline 23 & $\begin{array}{l}\text { Quão satisfeito(a) você está com as } \\
\text { condições do local onde mora? }\end{array}$ & 1 & 2 & 3 & 4 & 5 \\
\hline 24 & $\begin{array}{l}\text { Quão satisfeito(a) você está com o seu } \\
\text { acesso aos serviços de saúde? }\end{array}$ & 1 & 2 & 3 & 4 & 5 \\
\hline 25 & $\begin{array}{l}\text { Quão satisfeito(a) você está com o seu } \\
\text { meio de transporte? }\end{array}$ & 1 & 2 & 3 & 4 & 5 \\
\hline
\end{tabular}

As questões seguintes referem-se a com que freqüência você sentiu ou experimentou certas coisas nas últimas duas semanas.

\begin{tabular}{||l|l|c|c|c|c|c||}
\hline \hline 26 & nunca & $\begin{array}{c}\text { agumas } \\
\text { vezes }\end{array}$ & frequientemente & $\begin{array}{c}\text { muito } \\
\text { frequientemente }\end{array}$ & sempre \\
\hline $\begin{array}{l}\text { Com que freqüência você tem } \\
\text { sentimentos negativos tais como mau } \\
\text { humor, desespero, ansiedade, } \\
\text { depressão? }\end{array}$ & 1 & 2 & 3 & 4 & 5 \\
\hline
\end{tabular}

Alguém lhe ajudou a preencher este questionário?

Quanto tempo você levou para preencher este questionário?...

Você tem algum comentário sobre o questionário?

OBRIGADO PELA SUA COLABORAÇÃO 